OPEN ACCESS

Edited by:

Gail Scowcroft,

University of Rhode Island,

United States

Reviewed by:

Meghan E. Marrero,

Mercy College, United States

Jan Marcin Weslawski,

Institute of Oceanology (PAN), Poland

${ }^{*}$ Correspondence:

Matthew Ashley

matthew.ashley@plymouth.ac.uk

Specialty section:

This article was submitted to Marine Ecosystem Ecology,

a section of the journal

Frontiers in Marine Science

Received: 31 January 2019 Accepted: 17 May 2019

Published: 06 June 2019

Citation:

Ashley M, Pahl S, Glegg G and Fletcher S (2019) A Change of Mind:

Applying Social and Behavioral Research Methods to the Assessment of the Effectiveness of Ocean Literacy Initiatives. Front. Mar. Sci. 6:288. doi: 10.3389/fmars.2019.00288

\section{A Change of Mind: Applying Social and Behavioral Research Methods to the Assessment of the Effectiveness of Ocean Literacy Initiatives}

\author{
Matthew Ashley ${ }^{1 *}$, Sabine Pahl ${ }^{2}$, Gillian Glegg ${ }^{1}$ and Stephen Fletcher ${ }^{3}$ \\ ${ }^{1}$ School of Biological and Marine Sciences, University of Plymouth, Plymouth, United Kingdom, ${ }^{2}$ Faculty of Health and \\ Human Sciences, School of Psychology, University of Plymouth, Plymouth, United Kingdom, ${ }^{3}$ World Conservation \\ Monitoring Centre, UNEP, Cambridge, United Kingdom
}

Assessment of environmental literacy and ocean literacy focus on increasing knowledge and awareness. The goal of ocean literacy initiatives is ultimately to enable behavior change (whereby citizens take direct and sustainable action) to achieve sustainable solutions to marine environment issues. The application of social and behavioral research methods provides powerful tools for assessing if ocean literacy initiatives are effective at increasing participant's knowledge and awareness of an issue, its causes and consequences and behaviors or actions required to enable sustainable solutions. Social and behavioral research methods also provide a means of assessing changes in attitude, a key predictor of behavior change, and ultimately a means of assessing changes in a participants intended and reported behaviors. We present a framework to integrate social and behavioral research methods within assessment of the effectiveness of ocean literacy initiatives. The before and after assessment we undertake develops existing environmental literacy and ocean literacy assessment approaches by integrating social and behavioral research methods to assess key predictors of behavior change. We structured the assessment methodology within a Theory of Change logic model, to provide a protocol for systematic evaluation of ocean literacy initiatives and tools. Specifically those aimed at promoting specific behavior change objectives for pre-identified actors. Assessment of educational training courses for professionals entering the shipping industry (targeting behaviors to reduce the spread of invasive species), and educational workshops for school students (aged 11-15 and 16-18), on problems related to marine litter and microplastics and potential solutions were assessed using the framework. Through before and after surveys, an increase in awareness, knowledge and an increase in attitudes supporting action to reduce impacts on the marine environment were reported by participants, after interaction with sets of tools developed by the Horizon 2020 Ocean Literacy project ResponSEAble. Results supported the importance of targeting specific audiences with tailored ocean literacy tools and the importance of informing actors of issues and solutions within the context of wider ocean literacy principles.

Keywords: ocean literacy, behavioral science, effectiveness, education, attitude, sustainable development, intended behavior 


\section{INTRODUCTION}

The concept of Ocean Literacy, defined as, "understanding the oceans influence on you and your influence on the ocean." Schoedinger et al. (2005) underpins the concept of environmental or ocean or marine citizenship. "Ocean citizens" make informed lifestyle choices to minimize impacts on ocean health, and in so doing, contribute to solutions for large scale and seemingly insurmountable global problems (Hawthorne and Alabaster, 1999; Fletcher and Potts, 2007). Thereby, increasing ocean literacy across public, industry and governance actors provides a society-wide approach, to reduce environmental impacts and pro-actively generate positive change. As a result, negative implications for human societies, such as impacts on economic resources and human health are reduced. Within the United Nations revised roadmap for the "decade of ocean science for sustainable development," ocean literacy underpins targets for citizens and stakeholders to have a more responsible and informed behavior toward the ocean and its resources (United Nations, 2018).

Enhancing ocean awareness and knowledge is considered essential to increase support for solutions to reduce or cope with human impacts on the marine environment (Schoedinger et al., 2005). However, to reduce human impacts requires larger scale behavior change. As such, assessment of environmental or ocean literacy education and awareness raising interventions has begun to focus on changes in participant's attitude and behavior (Hartley et al., 2015, 2018a). Attitude and behavior changes, whereby, public and industry actions provide support for solutions to environmental problems, and take action, are, central to the goal of forming an ocean literate society. Collective action, stimulated by awareness, but fuelled by knowledge of behavior options to reduce impact and the attitude to take them, provides an opportunity to allow human impacts on the marine environment to be tackled over large scales, and enable sustainable development goals to be met (Hawthorne and Alabaster, 1999; Fletcher and Potts, 2007; United Nations, 2018).

The United Nations revised roadmap for the "decade of ocean science for sustainable development" identifies, under Research and Design Priority Area 7, that; "a rigorous ocean literacy programme of activities has to be designed. The major target audiences have to be school students, which requires including ocean literacy in the school curriculum, reaching out to decision-makers, governmental authorities, and the public at large" (United Nations, 2018). At a global scale the roadmap identifies the need to build capacities worldwide, including that; "all nations, stakeholders and citizens have access to ocean data and information, technologies and have the capacities to inform their decisions" (United Nations, 2018). To enable governments, stakeholders and citizens to undertake informed decisions the road map identified the importance of ocean literacy in Objective 1 of the strategic objectives; "To generate knowledge of the ocean system, its role in the earth and climate system, including the human component, its biodiversity and the seabed, to support sustainable management" (United Nations, 2018). The roadmap identifies that, for the public in particular; "increased awareness and ocean literacy will be instrumental in triggering behavioural changes, such as adaptation of lifestyles, joining non-government organisations (NGOs), choosing ocean-affiliated professions" (United Nations, 2018). Although an ocean literacy programme has already been identified as essential to increase in awareness and knowledge, and lead to informed decision making and to trigger behavior changes, assessment of effectiveness will be essential to ensure objectives are met. Assessment will be required to monitor if the initiatives within an ocean literacy programme achieve intended increases in awareness, knowledge and inform decisions and trigger behavior change.

Over the last decade, ocean literacy has largely focused on the development of education and engagement materials, for classrooms use and for the general public, including campaigns and messages communicated thorough media, exhibitions, filmmaking and story-telling (Schubel and Schubel, 2008; Bishop et al., 2015; Donert et al., 2015). Assessment of effectiveness of these activities has focused on assessing awareness and knowledge in relation to defined levels of ocean literacy (Schoedinger et al., 2005; Fauville et al., 2018). Existing perceptions of the public and other actors on relative importance of pressures on the marine environment, and concern regarding impacts have received attention (Gelcich et al., 2014; Potts et al., 2016; Buckley et al., 2017). Pre-existing pro-environmental behaviors undertaken by people have also been studied, as well as the relationship between level of knowledge, concern and the existing behaviors or actions undertaken (Muderrisoglu and Altanlar, 2011; Chen and Tsai, 2016). However, the effect of an ocean literacy initiative on behavior change objectives, for a given audience or actor are rarely assessed, despite the availability of behavioral and social science methods to achieve this (Hartley et al., 2015, 2018a; Pahl and Wyles, 2017).

Examples of cross-disciplinary research methods, to assess behavior change, already exist and have been applied in recent years for conservation projects (Andriamalala et al., 2013; Saypanya et al., 2013; Chaigneau and Daw, 2015), environmental literacy assessment (Muderrisoglu and Altanlar, 2011; Chen and Tsai, 2016) and ocean literacy interventions (Hartley et al., 2015, 2018a,b). Behavioral models used in these studies have been adapted from well-established approaches developed in behavioral sciences for effectiveness of health interventions and environmental education (Prochaska et al., 1992; Vaughan and Rogers, 2000; Jenks et al., 2010).

Systematic approaches to assessing change in attitude and behavior are valuable both in assessing the effectiveness of ocean literacy tools and for informing practitioners on the benefit of applying tools with specific audiences. Pahl and Wyles (2017) highlight that information (informing people) is sometimes considered as the key factor for changing perceptions and behavior by scientists outside of the behavioral sciences. Informing people (raising awareness) is a necessary step, but studies have revealed assessing awareness alone does not necessarily assess if a change in attitude and behavior has been adopted (Schultz, 1999; Steg et al., 2013). Pahl and Wyles (2017) conclude that understanding the influences of human thought and behavior is just as important. Incorporating existing systematic understanding of human behaviors and their underlying mechanisms, with empirical methods to collect data 
that explain perceptions and behavior, thereby, enables a greater level of assessment of interventions aimed at behavior change (Reddy et al., 2016; Pahl and Wyles, 2017).

The application of behavioral models and research techniques from psychology and behavioral sciences provides the opportunity for a greater level of understanding of uptake of messages from ocean literacy education tools. Most importantly, the research techniques allow for assessment of predictors of behavior change, including change in intended behavior. Perceived behavior control ("it is up to me whether I do this rather than other people or contextual factors") and intended behavior ("I will do this") were identified through review of environmental behavioral studies as the best direct predictors of behavior (Klöckner, 2013), and can be monitored through behavioral research techniques (Pahl and Wyles, 2017).

Both psychological research techniques and environmental literacy approaches such as the Environmental Literacy Ladder (ELL, 2007), identify the process or stages that are needed to be reached to achieve the end objective. This approach, starting with the end objective and working back through the stages that lead to it, can be effectively summarized in the Theory of Change approach (Connell and Kubisch, 1998). The Theory of Change logic model, maps out a path of how the desired behavior change, promoted by the ocean literacy initiatives, would be achieved (Connell and Kubisch, 1998). Saypanya et al. (2013) and Andriamalala et al. (2013) successfully applied a Theory of Change adapted from health research (Prochaska et al., 1992; Vaughan and Rogers, 2000; Jenks et al., 2010), to take a structured, systematic approach to achieving behavior change (support for conservation initiatives) in fishing communities and rural hunting communities in Madagascar and south-east Asia. The approach has resulted in reduction of hunting pressure on rare and endangered species and fishing pressures and fish stocks as a part of conservation programmes.

Each stage in a Theory of Change provides a step toward the ultimate objective (e.g., large-scale behavior change) (Connell and Kubisch, 1998; Jenks et al., 2010). Each step can be assessed by an indicator metric, in relation to the stated objective. Indicators and objectives can include responses to surveys, or quantitative evidence, such as an increased proportion of participants recycling or reducing purchase of single use plastic.

We applied a Theory of Change logic model to enable a systematic assessment of ocean literacy initiatives. Each stage in the Theory of Change moved toward the behavior change objective identified for the ocean literacy initiative. The stages moved from development of participant's knowledge of causes of the issues and the resulting consequences for marine life and human society, changes in their attitude to changes to their intention to take actions to address the issue. Each of these stages relate to predictors of behavior change, identified in behavioral science literature (Klöckner, 2013; Pahl and Wyles, 2017), and stages within the environmental literacy ladder (ELL, 2007). The aim of the work carried out, was to apply social and behavioral research methods, to assess the effectiveness of ocean literacy initiatives on influencing predictors of behavior change (Klöckner, 2013; Pahl and Wyles, 2017), and ultimately behavior post interaction with the intervention. The approach aims to build on existing studies of links between awareness, knowledge and concern for ocean environment issues (Gelcich et al., 2014; Buckley et al., 2017), studies of people's attitudes and pro-environmental behavior (Muderrisoglu and Altanlar, 2011) and changes in behavior post interaction with education tools (Hartley et al., 2015, 2018a).

To demonstrate the framework's application to assessment of ocean literacy education and awareness raising tools, the use of the Theory of Change logic model was demonstrated in two pilot studies. We assessed the effectiveness of "sustainable seafaring" educational courses undertaken by students training to become engineering and deck officers in the shipping industry, at a technical college in Basque Autonomous Community (aged 1625) (Study 1). We also assessed the effectiveness of ocean literacy films shown during educational workshops, at an aquarium in the UK, undertaken by school pupils (aged 11-15) and workshops undertaken by school aged students (11-15) and older teenagers (16-18) in Tulcea, Romania (Study 2). In the pilot studies we used a survey instrument, provided to participants pre and post interaction with the ocean literacy initiative, adapting the methods of Hartley et al. (2018a) to answer the following questions:

1. Do the ocean literacy tools influence predictors of behavior change?

2. Which predictor of behavior change shows the strongest relationship to participants support for behaviors promoted by the ocean literacy tool?

i) Does level of awareness and knowledge influence intended behavior?

ii) Does level of concern (attitude) influence intended behavior?

iii) Does perceived self-efficacy (confidence in ability to undertake the action or behavior) influence intended behavior?

\section{METHODS}

\section{Relating Predictors of Behavior Change to Ocean Literacy Tool Objectives}

We aligned the stages within the ELL (ELL, 2007), and the results of an integrative model, tested by Klöckner (2013), which identified the best predictors of environmentally conscious behavior, based on data from 56 data sets targeting different environmental behaviors (Table 1). The ten social and psychological concepts identified by Klöckner (2013) can be measured and distinguished empirically and provide a rich toolbox for changing behavior beyond information and knowledge provision (Pahl and Wyles, 2017). These provided the basis for "ocean literacy dimensions" that were applied as stages within the Theory of Change model adapted from health and conservation projects (Jenks et al., 2010; Saypanya et al., 2013) (Table 1).

\section{Defining Ocean Literacy Initiative (Tool) Objectives}

The ocean literacy educational and awareness raising initiatives (tools) we assessed were developed to address specific behavior 
TABLE 1 | Relationship between predictors of behavior change identified by Klöckner (2013), the ELL, TofC categories, and OL dimensions applied in this study.

\begin{tabular}{|c|c|c|c|}
\hline Predictors of behavior (KIöckner, 2013) & $\begin{array}{l}\text { Environmental Literacy } \\
\text { Ladder (ELL). (Text in } \\
\text { brackets indicates an } \\
\text { in-direct connection) }\end{array}$ & $\begin{array}{l}\text { Theory of change } \\
\text { stages } 1-5 \text { applied in } \\
\text { conservation } \\
\text { campaigns }\end{array}$ & $\begin{array}{l}\text { Ocean literacy dimensions applied in } \\
\text { assessment of effectiveness of ocean } \\
\text { literacy tools }\end{array}$ \\
\hline $\begin{array}{l}\text { Best direct predictors Intentions ("I will do this") } \\
\text { of behavior }\end{array}$ & $\begin{array}{l}\text { Collective action: capacity for } \\
\text { personal and collection action } \\
\text { and civic participation }\end{array}$ & Behavior & $\begin{array}{l}\text { Behavior decisions, choices, actions, and } \\
\text { habits, with respect to ocean related issues } \\
\text { (either intended behavior "I will do," } \\
\text { self-reported behavior "I do" and level of } \\
\text { repetition of behavior). Attitude } \\
\text { (self-efficacy): A belief in own ability to } \\
\text { address the issue and that personal actions will } \\
\text { be effective. Activism, the degree to which a } \\
\text { person engages in protesting and campaigning } \\
\text { to bring about political and social change }\end{array}$ \\
\hline
\end{tabular}

Perceived behavior control ("It is Skills: problem solving and

up to me whether I do this rather than critical thinking skills

other people or contextual factors")

Habits (behaviors that have become (Collective action) automatized through repetition)

Factors having an Norms (what is seen as commonly (Collective action) indirect effect on done by others)

behavior
Attitudes (favorable or unfavorable evaluations)

Attitudes: of appreciation and concern for the environment
Communication/ social norm

\section{Attitude}

Responsibility (ascriptions of who should deal with the problem)

Negative and positive emotions (such as worry or hope)

Values (general trans-situational goals such as equality or individualism)

Whether people see themselves as environmentalists

Awareness of consequences (knowledge about impacts)
Attitude

(Attitude)

(Attitude)

(Attitude)

(Attitude)

Knowledge, and understanding Knowledge

of human and natural systems

and processes

Awareness: general awareness Awareness of the relationship between the environment and human life
Communication: extent to which a person engages with ocean related information and how much they communicate about the ocean with family and friends (influence of the social norm)

Attitude: level of agreement with (favorable or unfavorable evaluations) or concern for a particular position, related to impacts and welfare in the DAPSIWR framework i.e., they exist, they are important, and a response is needed

Attitude (self-efficacy): A belief in own ability to address the issue and that personal actions will be effective

Attitude: Concern or worry about the issue

Attitude: Belief that it is important that society and individuals take actions to reduce or cope with the issue

Environmental connectedness: Emotional response to marine issues. Activism: the degree to which a person engages in protesting and campaigning to bring about political and social change

Knowledge: What a person knows about an ocean related topic and the links between topics (such as knowledge about impacts of human actions on the ocean environment)

Awareness: Basic knowledge that a situation, problem or concept exists change objectives, for specific actors in relation to key ocean literacy topics. The first tool, a 2 day course to educate young career professionals working as engineers or deck officers on board large ships focused on addressing the transport of introduction of invasive non-native species (as larvae) in ballast water. The second focused on addressing the issue of microplastics entering the sea through consumer's use of cosmetic products containing microplastics (Table 2).
The information within the tools and the actors to be targeted were selected through identifying actors and behavior change responses that could potentially have a large impact on reducing the negative impacts. These were identified through analysis of the interactions between the human and ocean systems, adapting the Driver-Activity-Pressure-State-Impact-Welfare (impact)Response (DAPSI(W)R) causal models (ResponSEAble, 2015; Elliott et al., 2017). In essence, the DAPSIWR approach 
provided the pre-intervention design and assessment process to identify the audience, and the behavior change message to reach objectives within behavior science planning and evaluation frameworks, such as the PRECEDE- PROCEED model (Green and Kreuter, 1999) and guiding questions identified by Reddy et al. (2016).

\section{Education Materials}

\section{Study 1. Two Day "Sustainable Seafaring" Course}

The "sustainable seafaring" course was developed within the ResponSEAble project by environmental education professionals, the "ProSea Foundation." The course was designed for students training as engineering and deck officers and early career professionals in the shipping industry. The course contained lecture material, short films, and group workshops and quizzes to provide background knowledge on marine ecology, including food webs and productivity in coastal and deep pelagic seas. Background knowledge was provided on ballast water treatment and International policy (compliance with the Ballast Water Management Convention standards). Case studies of impacts of invasive non-native species on the marine environment and human livelihoods were also provided. The economic benefits to the industry of ensuring ships and shipping businesses minimize environmental impacts were then discussed, in relation to people, planet and profit models. Participants were asked to discuss sustainability issues in workshops and groups. In particular, participants were asked to discuss actions they can take when working in roles as engineering or deck officers to aid sustainable seafaring. The courses aimed to highlight the profitability of companies that act sustainably and the advantages not only to the marine environment and human livelihoods, but to the competitiveness of shipping companies that operate sustainably in the eyes of clients.

\section{Study 2. Short Film (5 min) Produced by Professional Environment and Sustainability Filmmakers on the Topic of Microplastics}

The short film "Rethinking Plastic" was produced by the charity "TVE, Television for the Environment" within the ResponSEAble project. The film used interviews with leading academic experts, businesses and environmental charities and campaign groups that represent actors identified in the DAPSIWR causal model developed for the key story "microplastics" (specifically microplastics in cosmetics) (ResponSEAble, 2015). The film provided clear messages on the drivers of microplastic production, the activities supporting their use and the pressures on the state of the marine environment that leads to negative impacts on marine organisms, the environment and potentially human health and welfare. Responses were presented that can be undertaken by consumers, businesses, product manufacturers and local and national governments. It was designed to be appropriate for school students over 11 and general public of different ages, backgrounds, levels of knowledge and from different cultures. The film promoted specific actions viewers could take to reduce use and negative impact of microplastics in the marine environment. The film was shown as part of marine plastic and microplastic educational activities within the National Marine Aquarium, to school students aged 11-15.

\section{Construction of a Theory of Change Logic Model}

A Theory of Change logic model was constructed for assessment of ocean literacy initiatives within this study through collaboration with social and behavioral science researchers, tool developers and practitioners. The Theory of Change logic model identified the process by which the behavior change objective of the ocean literacy tool could be reached for the given audience. The Theory of Change steps related to predictors of behavior change identified in Table 1. Each stage in the Theory of Change models for both ocean literacy tools were discussed and objectives and indicators were set prior to the participants' interaction with the ocean literacy tool. The Theory of Change model for the "sustainable seafaring" education course for young professionals (conducted in Pasaia, Basque Autonomous Community, Spain) is displayed in Table 3. The Theory of Change model for the educational videos presented within workshops for school pupils (aged 11-15) (conducted at the National Marine Aquarium, Plymouth, UK) is displayed in Table 4.

\section{Participants and Recruitment}

In Study 1, a total of 17 students aged 18-44, participated from a technical college in Pasiaia, Basque Autonomous Community. The participants were recruited by course leaders and head teachers at the technical college, and were all in their final months of study before entering the shipping industry.

In Study 2, a total of 20 school students aged 12-15 years, participated in a viewing of the film "Rethinking Plastic" at an aquarium in Plymouth, UK. School students were recruited for the film viewing, from attendees of events run for UK teenagers as part of the aquariums "teen club" Ocean Squad events. The week long events are advertised nationally and participants can book on the aquarium website. Two workshop events, where the film was shown to participating students, were also run at two separate high schools (11-18 year old students), in Tulcea, Romania, organized in collaboration with teachers at the two schools.

Although sample sizes were small, all attendees at the events were provided opportunity to complete surveys. As this study intended to demonstrate the applicability of the assessment approach to assess effectiveness of an ocean literacy tool on a target audience, the results are relevant for the participant's, but the small sample size limits interpretation of the results in relation to a wider population. As only one set of participants interacting with the ocean literacy initiative completed surveys, we recognize the risk of not detecting influence of outside events or being able to increase confidence in results of effectiveness across different samples. Results were interpreted with caution and Bonferroni corrections were applied to ensure interpretations of significance of changes between pre and post results were conservative. 


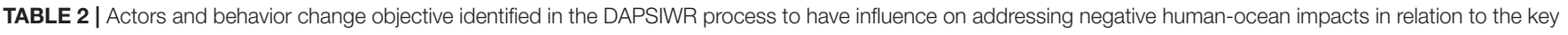
story topic (ResponSEAble, 2015).

\begin{tabular}{|c|c|c|c|}
\hline Key story & $\begin{array}{l}\text { Influential actor identified in } \\
\text { DAPSIWR }\end{array}$ & $\begin{array}{l}\text { Behavior change objective } \\
\text { identified in DAPSIWR }\end{array}$ & $\begin{array}{l}\text { Tool designed for education and } \\
\text { awareness raising (ocean literacy) for } \\
\text { relevant actor }\end{array}$ \\
\hline Microplastics in cosmetics & $\begin{array}{l}\text { General public and school pupils } \\
\text { (aged 11-15) }\end{array}$ & $\begin{array}{l}\text { Reduce or eliminate use of cosmetics } \\
\text { containing microplastics }\end{array}$ & $\begin{array}{l}\text { Educational films (based on DAPSIWR) } \\
\text { incorporated in aquarium workshops }\end{array}$ \\
\hline $\begin{array}{l}\text { Invasive non-native species } \\
\text { in ballast water }\end{array}$ & $\begin{array}{l}\text { Young professionals (seafarers) } \\
\text { training to enter shipping industry }\end{array}$ & $\begin{array}{l}\text { Support introduction of ballast water } \\
\text { cleaning systems and engage in best } \\
\text { practice in their operation }\end{array}$ & $\begin{array}{l}\text { Two day educational courses on workshops on } \\
\text { sustainable seafaring: including sections on } \\
\text { ballast water management and implications of } \\
\text { spreading invasive non-native species }\end{array}$ \\
\hline
\end{tabular}

\section{Survey Instrument to Assess Effectiveness of Ocean Literacy Tools}

Questions were informed by environmental psychology and education literature, to address the ocean literacy dimensions identified in Table 2. The survey instrument formed a quantitative evaluation that participants completed before they began the training course or film viewing (pre) and again after (post). It took approximately $10 \mathrm{~min}$ to answer these questions. The study was introduced, including an explanation of the informed consent process, by course leaders, prior to the survey being completed. Consent was sought from participants to participate in the studies prior to completing the questionnaire. Participant's were reminded that the survey was not a test and that their answers were anonymous and only their honest opinion was being asked for.

\section{Survey Question Development}

Questions were based on Hartley et al. (2015) with additional questions based on predictors of behavior change identified by Klöckner (2013). Question wording was adjusted to the topics approached by the ocean literacy education tools. Questions were developed with pre-test groups at University of Plymouth and Oceanopolis Aquarium, Brest. Language of questions was adjusted following feedback from the pre-test groups, to make understanding clearer. For instance, each questions language was adjusted to be jargon-free, unambiguous, and focused on a single issue per statement, if confusion was reported or observed in the pre-test groups. Language of end points of the 0-10 scale were also adjusted in this process to make extremes of viewpoints as clear as possible.

Questions were developed from existing proven measures and their face validity as a measure of knowledge, attitude, and intended behavior specifically, was reviewed in respect to original source questions. Content validity was maintained through application of the Theory of Change, relating to the predictors of behavior change identified in behavioral science literature, with each question measure relating to an indicator of an objective within the Theory of Change. Results of the pretest and the pilot studies were compared to results for similar knowledge, attitude and intended behavior measures, undertaken with study participants of comparable age and social background to assess convergent validity.
Internal reliability was assessed across the set of 5 intended behavior options provided by respondents to surveys before and after viewing the "Rethinking Plastic" film. Cronbach's coefficient alpha was calculated with a reliability coefficient of $>0.70$ considered as an indicator that the intended behavior measures were acceptable (Cronbach, 1990; Beanland et al., 1999; Pilot and Hungler, 1999). Cronbach's alpha identifies how closely related a set of items are as a group, and provides a measure of scale reliability. As all behavior actions relate to reducing or coping with a specific marine environmental issue, participant's responses to each individual behavior, would be expected, when combined, to be closely related to addressing the issue as a whole (a result between 0 and 1 of $>0.70$ ).

\section{Study 1 Questionnaire}

The pre-course questionnaire included eighteen questions. The questions were designed to assess participants' awareness of the issue, concern, knowledge, perceived understanding, belief and values, confidence and self-efficacy, communication about the issue, responsibility, and self-reported behaviors in relation to reducing or coping with the impacts of invasive nonnative species within ballast water. Further questions were designed to assess factors relating to participants' age, location, occupation, pre-existing concern for marine environmental issues and feedback on sources of information on environmental issues. (e.g., "I feel capable that when I start to work as a seafarer, I can reduce the spread of invasive species through my everyday actions").

Participants were asked to indicate their (dis)agreement with statements, or level of concern, or frequency of stated actions with response options from 0 to 10 , with end anchor points labeled "completely disagree," "not at all concerned," "not at all," and "completely agree," "very concerned," "all the time." Mid anchor points were included to guide participants following feedback from pilot studies ("neither agree/disagree," "moderately concerned," "some of the time"). The post-course questionnaire included the same questions as the pre-course questionnaire. Present tense was changed to future tense in relation to behavior questions to assess participants' intended behavior once they work as a seafarer.

\section{Study 2 Questionnaire}

A shorter survey tool, based on the same question design as Study 1 was used, but with a smaller range of questions and simplified 
TABLE 3 | Theory of Change model for the "sustainable seafaring" education course for young professionals.

\begin{tabular}{|c|c|c|c|c|c|c|}
\hline $\begin{array}{l}\text { Sustainable shipping } \\
\text { course theory of } \\
\text { change }\end{array}$ & Problem awareness & Knowledge & Attitude & Attitude-self efficacy & $\begin{array}{l}\text { Interpersonal } \\
\text { communication/social } \\
\text { norm }\end{array}$ & Behavior change \\
\hline Theory of Change: AIM & $\begin{array}{l}\text { Following the intervention } \\
\text { participants will be aware } \\
\text { (informed) of the issue or } \\
\text { problem in the key story }\end{array}$ & $\begin{array}{l}\text { Following the intervention } \\
\text { knowledge about the issue } \\
\text { (key story) will have } \\
\text { increased }\end{array}$ & $\begin{array}{l}\text { Following the intervention } \\
\text { attitude toward the issue } \\
\text { would have changed, and } \\
\text { change in behavior } \\
\text { supported }\end{array}$ & $\begin{array}{l}\text { Following the intervention } \\
\text { participants feel the } \\
\text { response action will be } \\
\text { effective and they have the } \\
\text { skills and knowledge } \\
\text { required }\end{array}$ & $\begin{array}{l}\text { Following the intervention } \\
\text { participants will } \\
\text { communicate about the } \\
\text { issue or topic with friends, } \\
\text { family and at work }\end{array}$ & $\begin{array}{l}\text { Behavior adopted or intention } \\
\text { expressed }\end{array}$ \\
\hline Measurable objective & $\begin{array}{l}\text { (i) After the course, mean } \\
\text { response of shipping } \\
\text { industry professionals } \\
\text { (participants) to the question } \\
\text { "how informed about the } \\
\text { effects of invasive species } \\
\text { on the marine } \\
\text { environment?" (0-10 scale) } \\
\text { will be } \geq 7 \text {. (ii) If pre course } \\
\text { response is }<7 \text {, effect size } \\
\text { (Cohen's d) will show a } \\
\text { medium or greater positive } \\
\text { effect }(\geq 0.8 \text { ) }\end{array}$ & $\begin{array}{l}\text { After the course, (i) mean } \\
\text { agreement of participants to } \\
\text { the statement "I have good } \\
\text { knowledge about how } \\
\text { invasive species effect } \\
\text { native marine life and how } \\
\text { invasive species may affect } \\
\text { human welfare." will be } \geq 7 \text {. } \\
\text { (ii) If pre course response is } \\
<7 \text {, effect size (Cohen's } d \text { ) } \\
\text { will show a medium or } \\
\text { greater positive effect } \\
\text { ( } \geq 0.8 \text { ). (iii) } \geq 75 \% \text { of } \\
\text { respondents will correctly } \\
\text { answer the knowledge quiz } \\
\text { question after the course }\end{array}$ & $\begin{array}{l}\text { After the course, (i) mean } \\
\text { response of participants to } \\
\text { the question "how } \\
\text { concerned are you about } \\
\text { the effects of invasive } \\
\text { species on native marine } \\
\text { life?" (0-10 scale) will be } \\
\geq 7 \text {. (ii) If pre course } \\
\text { response is }<7 \text { effect size } \\
\text { (Cohen's } d \text { ) will show a } \\
\text { medium or greater positive } \\
\text { effect ( } \geq 0.8) \text {. (iii) mean } \\
\text { agreement of participants to } \\
\text { the statement "I believe it } \\
\text { will be better for the ocean } \\
\text { environment and marine life, } \\
\text { if ballast water is treated" } \\
\text { (0-10 scale) will be } \geq 7 \text {. (iv) If } \\
\text { pre course response is }<7 \text {, } \\
\text { effect size (Cohen's } d \text { ) will } \\
\text { show a medium or greater } \\
\text { positive effect }(\geq 0.8)\end{array}$ & $\begin{array}{l}\text { After the course, (i) mean } \\
\text { agreement of participants to } \\
\text { the statement, "I feel } \\
\text { capable that when I start to } \\
\text { work as a seafarer, I can } \\
\text { reduce the spread of } \\
\text { invasive species through my } \\
\text { everyday actions," (0-10 } \\
\text { scale) will be } \geq 7 \text {. (ii) If pre } \\
\text { course response is }<7 \text {, } \\
\text { effect size (Cohen's } d \text { ) will } \\
\text { show a medium or greater } \\
\text { positive effect }(\geq 0.8)\end{array}$ & $\begin{array}{l}\text { After the course, (i) mean } \\
\text { response of participants to } \\
\text { the statement, "How often } \\
\text { do you talk about effective } \\
\text { means of helping to reduce } \\
\text { or cope with the effects of } \\
\text { invasive species with family, } \\
\text { friends, colleagues or } \\
\text { teachers," (0-10 scale) will } \\
\text { be } \geq 7 \text {. (ii) If pre course } \\
\text { response is }<7 \text {, effect size } \\
\text { (Cohen's d) will show a } \\
\text { medium or greater positive } \\
\text { effect }(\geq 0.8)\end{array}$ & $\begin{array}{l}\text { After the course, (i) mean } \\
\text { response of participants } \\
\text { reporting that they will undertake } \\
\text { actions to reduce or cope with } \\
\text { the effects of invasive species on } \\
\text { the marine environment, will be } \\
\geq 7 \text { on } 0-10 \text { scale. (ii) If pre } \\
\text { course response is }<7 \text {, effect } \\
\text { size (Cohen's d) will show a } \\
\text { medium or greater positive effect } \\
(\geq 0.8)\end{array}$ \\
\hline Indicator & $\begin{array}{l}\text { Pre-survey to post-survey } \\
\text { responses }\end{array}$ & $\begin{array}{l}\text { Pre-survey to post-survey } \\
\text { responses }\end{array}$ & $\begin{array}{l}\text { Pre-survey to post-survey } \\
\text { responses }\end{array}$ & $\begin{array}{l}\text { Pre-survey to post-survey } \\
\text { responses }\end{array}$ & $\begin{array}{l}\text { Pre-survey to post-survey } \\
\text { responses }\end{array}$ & $\begin{array}{l}\text { Pre-survey to post-survey } \\
\text { responses }\end{array}$ \\
\hline
\end{tabular}


TABLE 4 | Theory of Change model for the educational videos presented within workshops for school pupils (aged 11-15).

\begin{tabular}{|c|c|c|c|c|c|c|}
\hline $\begin{array}{l}\text { "Rethinking plastic" } \\
\text { educational video } \\
\text { theory of change }\end{array}$ & $\begin{array}{l}\text { Problem } \\
\text { awareness/knowledge }\end{array}$ & Knowledge & Attitude & $\begin{array}{l}\text { Attitude-belief in benefit } \\
\text { from own action } \\
\text { (self-efficacy) }\end{array}$ & $\begin{array}{l}\text { Interpersonal } \\
\text { communication/social } \\
\text { norm }\end{array}$ & Behavior change \\
\hline Theory of Change: AIM & $\begin{array}{l}\text { Following the intervention } \\
\text { participants will be aware } \\
\text { (informed) of the issue or } \\
\text { problem in the key story }\end{array}$ & $\begin{array}{l}\text { Following the intervention } \\
\text { knowledge about the issue } \\
\text { (key story) will have } \\
\text { increased }\end{array}$ & $\begin{array}{l}\text { Following the intervention } \\
\text { attitude toward the issue } \\
\text { would have changed, and } \\
\text { change in behavior } \\
\text { supported }\end{array}$ & $\begin{array}{l}\text { Following the intervention } \\
\text { participants feel the } \\
\text { response action will be } \\
\text { effective (there will be a } \\
\text { benefit) }\end{array}$ & $\begin{array}{l}\text { Following the intervention } \\
\text { participants will } \\
\text { communicate about the } \\
\text { issue or topic with friends, } \\
\text { family and at work or school }\end{array}$ & $\begin{array}{l}\text { Behavior adopted or intention } \\
\text { expressed }\end{array}$ \\
\hline Measurable objective & $\begin{array}{l}\text { (i) After the course, mean } \\
\text { response of participants } \\
\text { who watch the video and } \\
\text { take part in activities, to the } \\
\text { statements: "I have good } \\
\text { knowledge about how } \\
\text { microplastics effect native } \\
\text { marine life and how } \\
\text { microplastics may affect } \\
\text { human health?" (0-10 scale) } \\
\text { will be } \geq 7 \text {. (ii) If mean pre } \\
\text { course response is }<7 \text {, } \\
\text { effect size (Cohen's } d \text { ) will } \\
\text { show a medium or greater } \\
\text { positive effect }(\geq 0.8)\end{array}$ & $\begin{array}{l}\text { After the course, } \geq 75 \% \text { of } \\
\text { course participants will } \\
\text { correctly answer the ocean } \\
\text { literacy knowledge quiz } \\
\text { question (time in years a } \\
\text { plastic bottle takes to } \\
\text { degrade in the sea) }\end{array}$ & $\begin{array}{l}\text { (i) After the course mean } \\
\text { response of participants to } \\
\text { the question, "how worried } \\
\text { are you about the problems } \\
\text { microplastics in the sea } \\
\text { might cause?" (0-10 scale) } \\
\text { will be } \geq 7 \text {. (ii) If mean pre } \\
\text { course response is }<7 \text {, } \\
\text { effect size (Cohen's } d \text { ) will } \\
\text { show a medium or greater } \\
\text { positive effect }(\geq 0.8)\end{array}$ & $\begin{array}{l}\text { (i) After the course, mean } \\
\text { response of participants to } \\
\text { the statement: "I believe } \\
\text { there will be a benefit to the } \\
\text { health of the sea and } \\
\text { people's health if / stop } \\
\text { using products containing } \\
\text { micro-plastics," ( } 0-10 \text { scale) } \\
\text { will be } \geq 7 \text {. (ii) If mean pre } \\
\text { course response is }<7 \text {, } \\
\text { effect size (Cohen's } d \text { ) will } \\
\text { show a medium or greater } \\
\text { positive effect }(\geq 0.8)\end{array}$ & $\begin{array}{l}\text { (i) After the course, mean } \\
\text { response of participants to } \\
\text { the statement "How often } \\
\text { do you talk about ways of } \\
\text { helping to reduce the } \\
\text { problems microplastics may } \\
\text { cause in the sea with your } \\
\text { family, friends, colleagues or } \\
\text { teachers" (0-10 scale) will } \\
\text { be } \geq 7 \text {. (ii) If mean pre } \\
\text { course response is }<7 \text {, } \\
\text { effect size (Cohen's } d \text { ) will } \\
\text { show a medium or greater } \\
\text { positive effect }(\geq 0.8)\end{array}$ & $\begin{array}{l}\text { (i) After the course, mean } \\
\text { response of participants will be } \\
\geq 7 \text { for at least } 2 \text { intended } \\
\text { behavior options to "help reduce } \\
\text { the effects of micro-plastics on } \\
\text { the marine environment in the } \\
\text { future." (ii) If mean pre course } \\
\text { response is }<7 \text { for the options, } \\
\text { effect size (Cohen's } d \text { ) will show } \\
\text { a medium or greater positive } \\
\text { effect }(\geq 0.8) \text { for at least } 2 \text { options }\end{array}$ \\
\hline Indicator & $\begin{array}{l}\text { Pre-survey to post-survey } \\
\text { responses }\end{array}$ & $\begin{array}{l}\text { Pre-survey to post-survey } \\
\text { responses }\end{array}$ & $\begin{array}{l}\text { Pre-survey to post-survey } \\
\text { responses }\end{array}$ & $\begin{array}{l}\text { Pre-survey to post-survey } \\
\text { responses }\end{array}$ & $\begin{array}{l}\text { Pre-survey to post-survey } \\
\text { responses }\end{array}$ & $\begin{array}{l}\text { Pre-survey to post-survey } \\
\text { responses }\end{array}$ \\
\hline
\end{tabular}


language to make it more suitable for the younger sample. The questionnaire was completed with assistance of teachers and course leaders during an introduction session (pre) and again at the following day, after viewing the film (post). The questionnaire took about $10 \mathrm{~min}$ to complete.

The pre-course questionnaire included eleven questions designed to assess participants' awareness of the issue of microplastics entering the sea, general concern for damage to the environment, knowledge, perceived understanding, concern about effects of microplastics on marine life, belief and values, communication about the issue, and self-reported behaviors in relation to specific actions to help reduce or cope with the impacts of microplastics on the marine environment and human welfare. Further questions were designed to assess factors relating to participants' age, location, pre-existing concern for marine environmental issues and feedback on sources of information on environmental issues.

The post-course questionnaire included the same questions. Present tense was changed to future tense in relation to behavior questions to assess participants' intended behavior after completing the workshop.

\section{Analysis}

Analysis within both studies used the same approach, to test the effectiveness of the intervention on the participants in each case study example. Mean responses of the participants (on a scale of $0-10$ ) in relation to questions associated with each objective in the Theory of Change model were calculated for pre and post survey responses (Tables 3,4 ). To test significance of changes between pre and post survey responses, paired samples $t$-tests were calculated and significance defined with Bonferroni correction such that only comparisons with $p<0.005$ are interpreted as significant. Effect size Cohen's d was reported, calculated by taking the difference between the two means and dividing by the pooled standard deviation (i.e., the root mean square of the two SDs). Cohen's $d$ accounts for sample size, and so provided a suitable test for effect size of changes between pre and post responses, for the limited number of respondents in the pilot studies. Here, 0.20 is considered a small effect, 0.50 is medium, 0.80 is large, and $>1.20$ is very large effect. Where effect size was high, greater confidence could be provided in significant associations identified by $t$-tests, even with smaller sample size. The extent to which predictors of behavior (level of knowledge, agreement with attitude statements and, for study 1 participants level of confidence and self-efficacy, in post surveys) predicted participants intended frequency of undertaking ocean literate behavior in post surveys were assessed using linear regression calculations to provide $r^{2}$ values to assess relationships.

\section{RESULTS}

\section{Study 1}

\section{Objectives in Theory of Change}

Pre and post survey responses were used to assess if objectives within the Theory of Change for the "Sustainable Seafaring" course had been met (Table 5, Figure 1). Knowledge, attitude and intended indicator objectives were met, as they increased significantly between pre and post survey responses, even with Bonferroni corrections, providing confidence that there is only an exceptionally small opportunity the difference could have occurred by chance $(p \leq 0.005)$. After completing the course, participants reported they were significantly more informed about invasive species $t_{(16)}=8.14, p<0.001, d=2.5$, and had greater knowledge of the effects of invasive species on the marine environment $t_{(16)}=6.06, p<0.001, d=1.5$, and human welfare $t_{(16)}=-6.23, p<0.001, d=1.72$. Significant changes were also observed in participant's attitudes. Their concern about the effects of invasive species on native marine life increased $t_{(16)}=6.94, p<0.001, d=1.8$, as did their belief that there would be a benefit from treatment of ballast water $t_{(16)}=4.56, p<0.001$, $d=1.4$.

Belief that there would be a benefit from treatment of ballast water received almost complete mean agreement [mean agreement $=9(\mathrm{SE} \pm 0.2)]$, after the course. Participants agreement that, after the course, they felt capable that they can reduce the spread of invasive species through everyday actions as seafarers showed a small positive change $t_{(16)}=1.32, p<0.1$, $d=0.4$. Self-reported frequency of communication with friends, family and colleagues about effective ways of helping to reduce or cope with the effects of invasive species showed a significant increase after the course $t_{(16)}=2.34, p=0.02, d=0.5$.

After completing the course, the class, who were in their final months of training before entering the seafaring industry reported a strong intention to frequently undertake actions to reduce or cope with the effects of invasive species on the marine environment $[$ mean response $=7.7(\mathrm{SE} \pm 0.4)$ on 0 (not at all)-10 (all the time) scale]. This represented a significant positive change from before reported frequency of actions undertaken prior to the course $t_{(16)}=4.37, p<0.001, d=1.4$.

Students increased their perceptions of the effectiveness for all options to reduce or cope with the spread of invasive species. Before the course, perceived effectiveness was moderately high for the options involving, (i), "crew to undertake best practice in operation of ballast water treatment," (ii), "ships to have effective ballast water treatment systems," and d), "research to investigate spread of invasive species and effectiveness of treatment systems." The range of responses (on the 0-10 scale) for all three options pre course was between 7.0 and 7.2 and increased to between 8.2 and 8.6. Perceived effectiveness was moderate for the option, "new ships to be constructed using ballast free designs." Following the course there was a significant increase in perceived effectiveness of construction of ballast free ships $t_{(16)}=1.74, p<0.05, d=0.8$. Effect size (Cohens $d$ ) showed a large positive effect between pre and post course surveys for all options $(d=\geq 0.8)$. Despite the small sample size, large effect sizes (Cohens $d$ ) support the significant increase observed in the $t$-test result for these intended behaviors, as well as other predictors of behavior change, to undertake or support actions to reduce or cope with the effects of invasive species on the marine environment.

\section{Pre-existing Environmental Connectedness}

Before the course, the mean self-reported awareness of environmental issues, and concern about damage to the 
TABLE 5 | Summary of results of pre ad post surveys in relation to objectives within the "Sustainable Seafaring" course theory of change.

\begin{tabular}{|c|c|c|c|c|c|c|}
\hline & Problem awareness & Knowledge & Attitude & Attitude - self efficacy & $\begin{array}{l}\text { Interpersonal } \\
\text { communication/social } \\
\text { norm }\end{array}$ & Behavior \\
\hline Objective & $\begin{array}{l}\text { (i) After the course, mean } \\
\text { response of shipping industry } \\
\text { professionals (participants) to the } \\
\text { question "how informed about } \\
\text { the effects of invasive species on } \\
\text { the marine environment?" (0-10 } \\
\text { scale) will be } \geq 7 \text {. (ii) If pre course } \\
\text { response is }<7 \text {, effect size } \\
\text { (Cohen's d) will show a medium } \\
\text { or greater positive effect }(\geq 0.8)\end{array}$ & $\begin{array}{l}\text { After the course, (i) mean } \\
\text { agreement of participants to } \\
\text { the statement "I have good } \\
\text { knowledge about how } \\
\text { invasive species effect } \\
\text { native marine life and how } \\
\text { invasive species may affect } \\
\text { human welfare." will be } \geq 7 \text {. } \\
\text { (ii) If pre course response is } \\
<7 \text {, effect size (Cohen's } d \text { ) } \\
\text { will show a medium or } \\
\text { greater positive effect } \\
\text { ( } \geq 0.8 \text { ). (iii) } \geq 75 \% \text { of } \\
\text { respondents will correctly } \\
\text { answer the knowledge quiz } \\
\text { question after the course }\end{array}$ & $\begin{array}{l}\text { After the course, (i) mean } \\
\text { response of participants to } \\
\text { the question "how } \\
\text { concerned are you about } \\
\text { the effects of invasive } \\
\text { species on native marine } \\
\text { life?" (0-10 scale) will be } \\
\geq 7 \text {. (ii) If pre course } \\
\text { response is }<7 \text { effect size } \\
\text { (Cohen's d) will show a } \\
\text { medium or greater positive } \\
\text { effect ( } \geq 0.8) \text {. (iii) Mean } \\
\text { agreement of participants to } \\
\text { the statement "I believe it } \\
\text { will be better for the ocean } \\
\text { environment and marine life, } \\
\text { if ballast water is treated" } \\
\text { (0-10 scale) will be } \geq 7 \text {. (iv) If } \\
\text { pre course response is }<7 \text {, } \\
\text { effect size (Cohen's } d \text { ) will } \\
\text { show a medium or greater } \\
\text { positive effect ( } \geq 0.8 \text { ) }\end{array}$ & $\begin{array}{l}\text { After the course, (i) mean } \\
\text { agreement of participants to } \\
\text { the statement, "I feel } \\
\text { capable that when I start to } \\
\text { work as a seafarer, I can } \\
\text { reduce the spread of } \\
\text { invasive species through my } \\
\text { everyday actions," (0-10 } \\
\text { scale) will be } \geq 7 \text {. (ii) If pre } \\
\text { course response is }<7 \text {, } \\
\text { effect size (Cohen's } d \text { ) will } \\
\text { show a medium or greater } \\
\text { positive effect }(\geq 0.8)\end{array}$ & $\begin{array}{l}\text { After the course, (i) mean } \\
\text { response of participants to } \\
\text { the statement, "How often } \\
\text { do you talk about effective } \\
\text { means of helping to reduce } \\
\text { or cope with the effects of } \\
\text { invasive species with family, } \\
\text { friends, colleagues or } \\
\text { teachers," (0-10 scale) will } \\
\text { be } \geq 7 \text {. (ii) If pre course } \\
\text { response is }<7 \text {, effect size } \\
\text { (Cohen's } d) \text { will show a } \\
\text { medium or greater positive } \\
\text { effect }(\geq 0.8)\end{array}$ & $\begin{array}{l}\text { After the course, (i) mean } \\
\text { response of participants } \\
\text { reporting that they will undertake } \\
\text { actions to reduce or cope with } \\
\text { the effects of invasive species on } \\
\text { the marine environment, will be } \\
\geq 7 \text { on } 0-10 \text { scale. (ii) If pre } \\
\text { course response is }<7 \text {, effect } \\
\text { size (Cohen's d) will show a } \\
\text { medium or greater positive effect } \\
(\geq 0.8)\end{array}$ \\
\hline Result & $\begin{array}{l}\text { (i), Mean response (post) }=8.4 \\
(\mathrm{SE} \pm 0.3 \text { ) } \\
\text { (ii) Mean response (pre) }=4.7 \\
(\mathrm{SE} \pm 1.2 \text { ) Cohens } d=2.5\end{array}$ & $\begin{array}{l}\text { (i), Mean response post } \\
\text { (environment) }=7.6 \\
\text { (SE } \pm 0.3 \text { ) (welfare) }=7.7 \\
\text { (SE } \pm 0.3 \text { ) } \\
\text { (ii) Mean response pre } \\
\text { (environment) }=4.7 \\
\text { (SE } \pm 0.6) \text { Cohens } d=1.5 \\
\text { (welfare) }=4.9 \text { (SE } \pm 0.5 \text { ) } \\
\text { Cohens } d=1.7 \text {. Correct } \\
\text { answer }=88 \%\end{array}$ & $\begin{array}{l}\text { (i), Mean response post } \\
\text { (concern) }=8.29(\mathrm{SE} \pm 0.3) \\
\text { (belief) }=9(\mathrm{SE} \pm 0.2) \\
\text { (ii) Mean response pre } \\
\text { (concern) }=5.2(\mathrm{SE} \pm 0.5) \\
\text { Cohens } d=1.8 \\
\text { (belief) }=6.8(\mathrm{SE} \pm 0.5) \\
\text { Cohens } d=1.4\end{array}$ & $\begin{array}{l}\text { (i), Mean response } \\
\text { (post) }=7.6(\mathrm{SE} \pm 0.3) \\
\text { (ii) Mean response } \\
\text { (pre) }=6.8(\mathrm{SE} \pm 0.5) \\
\text { Cohens } d=0.4\end{array}$ & $\begin{array}{l}\text { (i), Mean response } \\
\text { (post) }=5.4(\mathrm{SE} \pm 0.7) \text { (ii) } \\
\text { Mean response }(\text { pre) }=4.0 \\
(\mathrm{SE} \pm 0.7) \text { Cohens } d=0.5\end{array}$ & $\begin{array}{l}\text { (i), Mean response (post) }=7.7 \\
\text { (SE } \pm 0.4 \text { ) } \\
\text { (ii) Mean response (pre) }=4.7 \\
\text { (SE } \pm 0.7 \text { ) Cohens } d=1.4\end{array}$ \\
\hline $\begin{array}{l}\text { Objective } \\
\text { achieved? }\end{array}$ & (i) $Y$, (ii) $Y$ & (i) $Y$, (ii) $Y$, (iii) $Y$ & (i) $Y$, (ii) $Y$, (iii) $Y$, (iv) $Y$ & (i) $\mathrm{Y}$, (ii) $\mathrm{N}$ & (i) $\mathrm{N}$, (ii) $\mathrm{N}$ & (i) $Y$, (ii) $Y$ \\
\hline
\end{tabular}

achieved?

Yes/No 
AWARENESS How informed do you feel about the effects of invasive species

Self Reported KNOWLEDGE - Effects on marine life

Self Reported KNOWLEDGE - Effects on availability of seafood

ATTITUDE - General environmental concern

ATTITUDE - Concern for effects of invasive species

ATTITUDE - Belief in benefits from treatment of ballast water

SELF EFFICACY - Feel capable can reduce the spread of invasive species through own actions

RESPONSIBILITY - New 'ballast free' ships to be constructed

RESPONSIBILITY - Crew follow best practice in operation of ballast water system

RESPONSIBILITY - All ships to have effective ballast water treatment systems

RESPONSIBILITY - Research into spread of invasive species and methods to reduce impacts

COMMUNICATION - How often talk about the issue of invasive species and ways to reduce impacts with others

Self Reported BEHAVIOUR - Undertake actions to reduce the spread and impacts of invasive species

$\square$ pre
$\square$ post

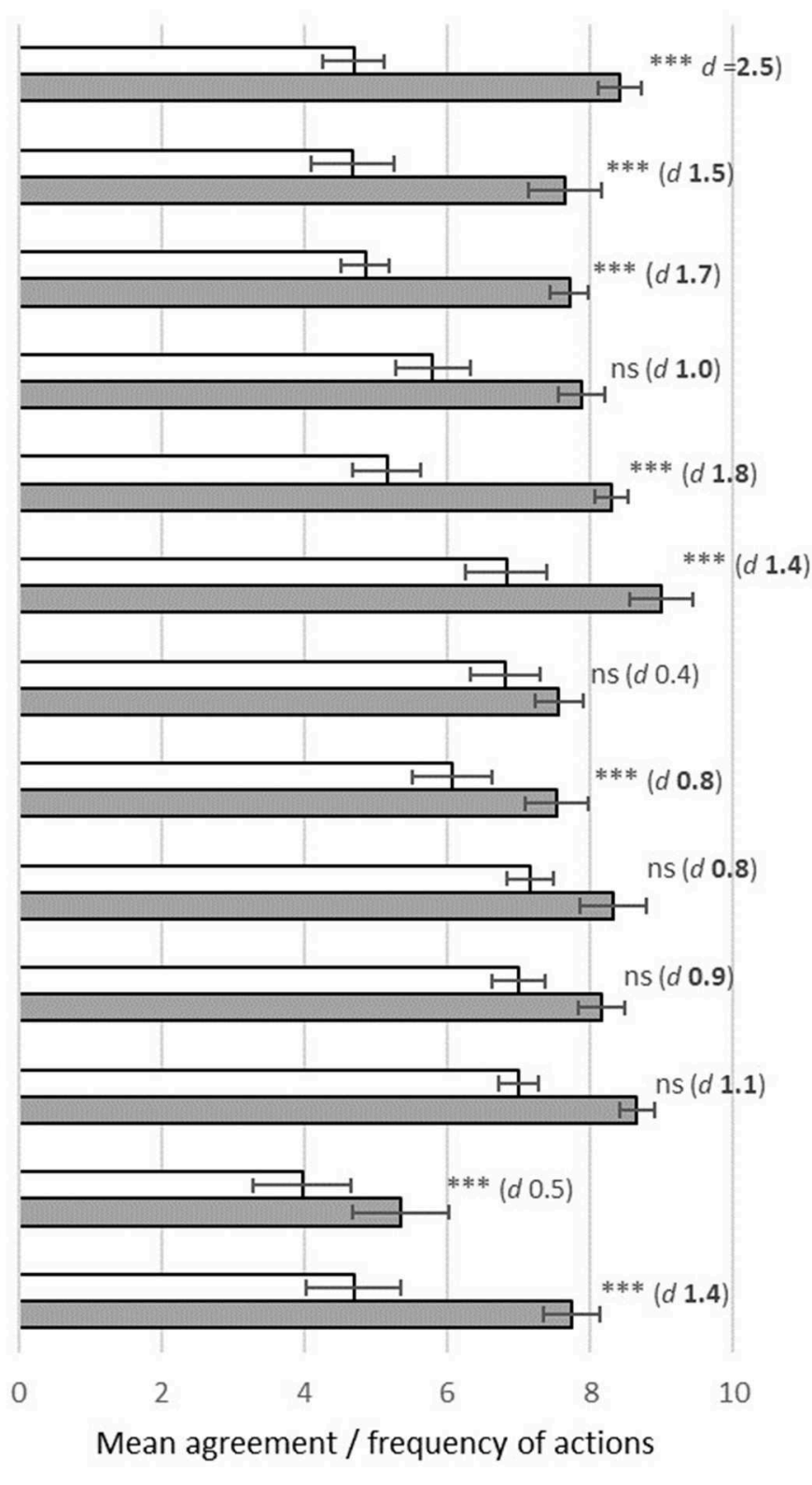

FIGURE 1 | Mean participant responses to pre and post surveys completed before and after participating in the "Sustainable Seafaring" course, significant differences $(p \leq 0.005)$ between pre and post surveys are indicated by ${ }^{\star \star \star}$, effect size (Cohen's $\left.d\right)$ of medium or above are in bold $(d=\#)$.

natural environment was moderately high for the student group [mean 7.2 (SE \pm 0.5 ) and mean 7.5 (SE \pm 0.5$)$, respectively]. Agreement with the statement "I always think about how my actions effect the marine environment" was moderate before the course (pre) (5.8 SE \pm 0.6 ). Proportion of the student group expressing awareness, concern or reflection on the effect of actions on the marine environment, higher than a moderate level ( $>6)$, before the course, was $65 \%$ (aware), 75\% (concern), 35\% (reflection on effect of actions). All respondents lived between 0 and 1.8 kilometers from the coast.

\section{Influence of Knowledge, Awareness, and Attitude} Ocean Literacy Dimensions on Intended Behavior

For post course responses, the results of linear regression calculations ( $r^{2}$ values) between each predictor of behavior change and student's level of intention to undertake actions showed weak relationships for all predictors of behavior change (Table 6). No significant relationship was present (Table 6). Low $r^{2}$ values in a range between 0 and 1 , suggest a larger deviation of the sample data from the modeled "line of best fit." The value would be expected to be greater and thereby, data closer to the line of best fit, if one variable strongly predicted the 
TABLE 6 | Linear regression calculations to assess extent to which predictors of behavior change (awareness, knowledge, attitude, self-efficacy and social norm) predict participants self-reported intended frequency of undertaking behaviors or actions to reduce the effects of invasive species on native marine life.

\begin{tabular}{|c|c|c|c|}
\hline \multirow[t]{2}{*}{$\begin{array}{l}\text { Ocean Literacy dimension, correlated } \\
\text { with intended behavior }(0-10)\end{array}$} & \multicolumn{3}{|c|}{$\begin{array}{l}\text { Intended frequency of } \\
\text { undertaking behaviors or actions } \\
\text { (post intervention) }\end{array}$} \\
\hline & $\boldsymbol{F}$ & $\boldsymbol{P}$ & $r^{2}$ \\
\hline $\begin{array}{l}\text { "Pre-existing pro-environmental attitude" } \\
\text { "I am concerned about damage to the } \\
\text { natural environment" }\end{array}$ & 1.185 & 0.29 & 0.078 \\
\hline $\begin{array}{l}\text { "Pre-existing pro-environmental attitude" } \\
\text { "I always think about how my actions } \\
\text { affect the environment" }\end{array}$ & 2.165 & 0.16 & 0.126 \\
\hline "How informed" (0-10) & 1.224 & 0.29 & 0.075 \\
\hline "Knowledge" (environment) (0-10) & 1.380 & 0.26 & 0.084 \\
\hline "Knowledge" (human welfare) (0-10) & 0.097 & 0.76 & 0.006 \\
\hline "Attitude" Concern (0-10) & 0.131 & 0.72 & 0.009 \\
\hline "Attitude" Belief in benefits of action (0-10) & 1.544 & 0.23 & 0.093 \\
\hline $\begin{array}{l}\text { "Self-efficacy" Feel capable can reduce } \\
\text { impact through own actions (0-10) }\end{array}$ & 0.374 & 0.55 & 0.026 \\
\hline $\begin{array}{l}\text { "Responsibility" Crew follow best practice } \\
(0-10)\end{array}$ & 0.011 & 0.92 & 0.001 \\
\hline $\begin{array}{l}\text { "Communication" with others about } \\
\text { impacts }(0-10)\end{array}$ & 0.168 & 0.17 & 0.123 \\
\hline
\end{tabular}

other. It is important to consider that the small sample size may limit effectiveness of this analysis and results should be interpreted with caution. A greater number of respondent's for pre and post surveys would provide greater confidence in the association between the data and line of best fit generated by the linear model. There may also be differences between each individual respondent's motivation for their intended frequency of undertaking behaviors. It must be considered that there may be a more complex interaction between level of knowledge, level of attitude and considerations such as socially expected behaviors that influence behavior intention, than are expressed in the results of the linear regression calculations.

\section{Study 2 \\ Objectives in Theory of Change}

As with the seafaring course, pre and post survey responses were used to assess if objectives within the Theory of Change for the "Rethinking plastic" film presented within the NMA activities, in Plymouth, UK and showings in Tulcea, Romania had been met (Table 7, Figure 1). All indicators for each objective were met, apart from $26 \%$ of participants still got the quiz question wrong (on number of years a plastic bottle takes to degrade in the sea), and although the level students reported talking about the issue with other increased between pre and post surveys, frequency of communicating about the issue was still moderate. For all other indicators of objectives, indicator objectives were met. There were significant differences between pre and post survey responses, even with Bonferroni corrections, providing confidence that there is only an exceptionally small opportunity the difference could have occurred by chance $(p \leq 0.005)$.

After viewing the film and participating in the activities, participants self-reported knowledge about (i), how microplastics effect marine life and (ii), how microplastics may affect human health, had significantly increased [marine life $t_{(15)}=4.7, p<$ $0.005, d=5.99$, human welfare $\left.t_{(15)}=3.49, p<0.005, d=4.6\right]$ (Figure 1). Before the course $71 \%$ of participants answered the knowledge question "How long does a plastic bottle take to degrade in the ocean?" After the course $75 \%$ of participants answered the question correctly.

Participants pre-existing concern for damage to the natural environment and concern for the effects of microplastics on marine life was high at the start of the study (natural environment, mean 8.86 SE \pm 0.18 , effects of microplastics, mean 8.36 SE \pm 0.21 ) (Figure 2). Concern remained high or showed a small increase after the viewing the film, a small to moderate positive effect size occurred for concern for effects of microplastics [concern about damage to the environment $t_{(32)}=0.47, p=0.64, d=0.07$, concern about effects of microplastics $t_{(31)}=1.08, p=0.29, d=0.24$ ]. Participant's level of agreement with the statement that, "I believe there will be a benefit to the health of the sea and people's health if I stop using products containing micro-plastics," was also high before viewing the film (mean 8.42 SE \pm 0.25 ) and showed a small increase after the event (mean 8.52 SE \pm 0.32$)\left[t_{(30)}=1.01, p=0.32\right.$, $d=0.06]$ (Figure 2).

Self-reported frequency of communication with friends, family and colleagues about, "ways of helping to reduce the problems microplastics may cause in the sea." showed an increase after the course $t_{(32)}=1.09, p=0.28, d=0.19$ (Figure 2).

After completing the course, the participants who were attending the event from across the UK, reported a strong intention to frequently undertake all actions to: "help reduce the effects of micro-plastics on the marine environment in the future." Self-reported frequency of undertaking the action: "separating plastics for recycling" was already high (mean) in the pre intervention survey, and there was still a small increase in frequency participants intended to undertake this action in the future $t_{(30)}=2.35, p=0.02, d=0.5$ (Figure 2). Before the event, participants reported a moderate frequency of "looking for products that use packaging that can be recycled" (Mean 6.3 SE \pm 0.43 ) and after the event a greater frequency of undertaking the action was intended (mean 7.4 SE \pm 0.43 ) although with Bonferroni correction the change was not significant $t_{(30)}=2.85$, $p=0.007, d=0.33$ (Figure 2). Significant increases occurred in frequency participants reported they would undertake the actions "looking for products that don't contain microplastics," and, "supporting shops that don't sell products containing microplastics" [look for products $t_{(30)}=4.92, p=<0.005$, $d=0.8$, supporting shops, $\left.t_{(30)}=4.59, p=<0.005, d=0.48\right]$ (Figure 2). Despite moderate sample sizes, medium to large effect sizes (Cohens $d$ ) support the significant increase observed in the $\mathrm{t}$-test result for these intended behaviors to reduce use of products containing microplastics.

Cronbach's alpha values calculated across responses to current frequency of behaviors and intended behavior 
TABLE 7 | Summary of results of pre and post surveys in relation to objectives in the theory of change related to participants' viewing the "Rethinking Plastic" film.

\begin{tabular}{|c|c|c|c|c|c|c|}
\hline & Problem awareness/knowledge & Knowledge & Attitude (concern) & $\begin{array}{l}\text { Attitude-[belief in } \\
\text { benefit from own action } \\
\text { (self-efficacy)] }\end{array}$ & $\begin{array}{l}\text { Interpersonal } \\
\text { communication/social } \\
\text { norm }\end{array}$ & Behavior change \\
\hline Objective & $\begin{array}{l}\text { (i) After the course, mean response of } \\
\text { participants who watch the video and } \\
\text { take part in activities, to the } \\
\text { statements: "I have good knowledge } \\
\text { about how microplastics effect native } \\
\text { marine life and how microplastics } \\
\text { may affect human health?" (0-10 } \\
\text { scale) will be } \geq 7 \text {. (ii) If mean pre } \\
\text { course response is }<7 \text {, effect size } \\
\text { (Cohen's d) will show a medium or } \\
\text { greater positive effect }(\geq 0.8)\end{array}$ & $\begin{array}{l}\text { After the course, } \geq 75 \% \text { of } \\
\text { course participants will } \\
\text { correctly answer the ocean } \\
\text { literacy knowledge quiz } \\
\text { question (time in years a } \\
\text { plastic bottle takes to } \\
\text { degrade in the sea) }\end{array}$ & $\begin{array}{l}\text { (i) After the course mean } \\
\text { response of participants to } \\
\text { the question, "how worried } \\
\text { are you about the problems } \\
\text { microplastics in the sea } \\
\text { might cause?" (0-10 scale) } \\
\text { will be } \geq 7 \text {. (ii) If mean pre } \\
\text { course response is }<7 \text {, } \\
\text { effect size (Cohen's d) will } \\
\text { show a medium or greater } \\
\text { positive effect }(\geq 0.8)\end{array}$ & $\begin{array}{l}\text { (i) After the course, mean } \\
\text { response of participants to } \\
\text { the statement: "I believe } \\
\text { there will be a benefit to the } \\
\text { health of the sea and } \\
\text { people's health if / stop } \\
\text { using products containing } \\
\text { micro-plastics," (0-10 scale) } \\
\text { will be } \geq 7 \text {. (ii) If mean pre } \\
\text { course response is }<7 \text {, } \\
\text { effect size (Cohen's } d \text { ) will } \\
\text { show a medium or greater } \\
\text { positive effect }(\geq 0.8)\end{array}$ & $\begin{array}{l}\text { (i) After the course, mean } \\
\text { response of participants to } \\
\text { the statement "How often } \\
\text { do you talk about ways of } \\
\text { helping to reduce the } \\
\text { problems microplastics may } \\
\text { cause in the sea with your } \\
\text { family, friends, colleagues or } \\
\text { teachers" ( } 0-10 \text { scale) will } \\
\text { be } \geq 7 \text {. (ii) If mean pre } \\
\text { course response is }<7 \text {, } \\
\text { effect size (Cohen's } d \text { ) will } \\
\text { show a medium or greater } \\
\text { positive effect }(\geq 0.8)\end{array}$ & $\begin{array}{l}\text { (i) After the course, mean } \\
\text { response of participants will be } \\
\geq 7 \text { for at least } 2 \text { intended } \\
\text { behavior options to "help reduce } \\
\text { the effects of micro-plastics on } \\
\text { the marine environment in the } \\
\text { future." (ii) If mean pre course } \\
\text { response is }<7 \text { for the options, } \\
\text { effect size (Cohen's } d \text { ) will show } \\
\text { a medium or greater positive } \\
\text { effect }(\geq 0.8 \text { ) for at least } 2 \text { options }\end{array}$ \\
\hline Result & $\begin{array}{l}\text { (i), Mean response post } \\
\text { (environment) }=7.97 \text { (SE } \pm 0.29 \text { ) } \\
\text { (welfare) }=7.54 \text { (SE } \pm 0.34 \text { ) (ii) } \\
\text { Environment Cohens } d=1.05 \\
\text { welfare Cohens } d=0.95\end{array}$ & $\begin{array}{l}\text { Correct answer } \\
\text { (post) }=74 \%\end{array}$ & $\begin{array}{l}\text { (i), Mean response } \\
\text { (post) }=8.57(\mathrm{SE} \pm 0.28) \\
\text { (ii) Mean response } \\
\text { (pre) }=8.36(\mathrm{SE} \pm 0.21) \\
\text { Cohens } d=0.24\end{array}$ & $\begin{array}{l}\text { (i), Mean response } \\
\text { (post) }=8.52(\mathrm{SE} \pm 0.32) \\
\text { (ii) Mean response } \\
\text { (pre) }=8.42(\mathrm{SE} \pm 0.25) \\
\text { Cohens } d=0.06\end{array}$ & $\begin{array}{l}\text { (i), Mean response } \\
\text { (post) }=5.57(\mathrm{SE} \pm 0.41) \\
\text { (ii) Mean response } \\
\text { (pre) }=5.11(\mathrm{SE} \pm 0.42 \text { ) } \\
\text { Cohens } d=0.19\end{array}$ & $\begin{array}{l}\text { (i), Mean response (post) }=>7 \text { for } \\
\text { all behaviors } \\
\text { (ii) Mean response (pre) }=5.69 \\
\text { across behavior options. Cohens } \\
d=>0.8 \text { for } 2 \text { behavior options }\end{array}$ \\
\hline Objective & (i) $Y$, (ii) $Y$ & (iv) $\mathrm{N}$ & (i) $\mathrm{Y}$, (ii) $Y$ (all ready > 7) & (i) $\mathrm{Y}$, (ii) $Y$ (all ready > 7) & (i) $\mathrm{N}$, (ii) $\mathrm{N}$ & (i) $Y$, (ii) $Y$ \\
\hline
\end{tabular}

achieved?

Yes/No 
Self Reported KNOWLEDGE - Effects on marine life

Self Reported KNOWLEDGE - Effects may have on human health

ATTITUDE - General environmental concern

ATTITUDE - Concern (worry) about problems microplastics cause in the sea

ATTITUDE - Belief in benefits to the health of the sea if stop using products containing microplastics

COMMUNICATION - How often talk about helping to reduce the problems of plastic litter may cause in the sea with others

BEHAVIOUR - Look for products that use packaging that can be recycled

BEHAVIOUR - Look for products without micropastics

BEHAVIOUR - Support shops that don't sell microplastics

BEHAVIOUR - Support campaigns

BEHAVIOUR - Separate plastics for recycling

0

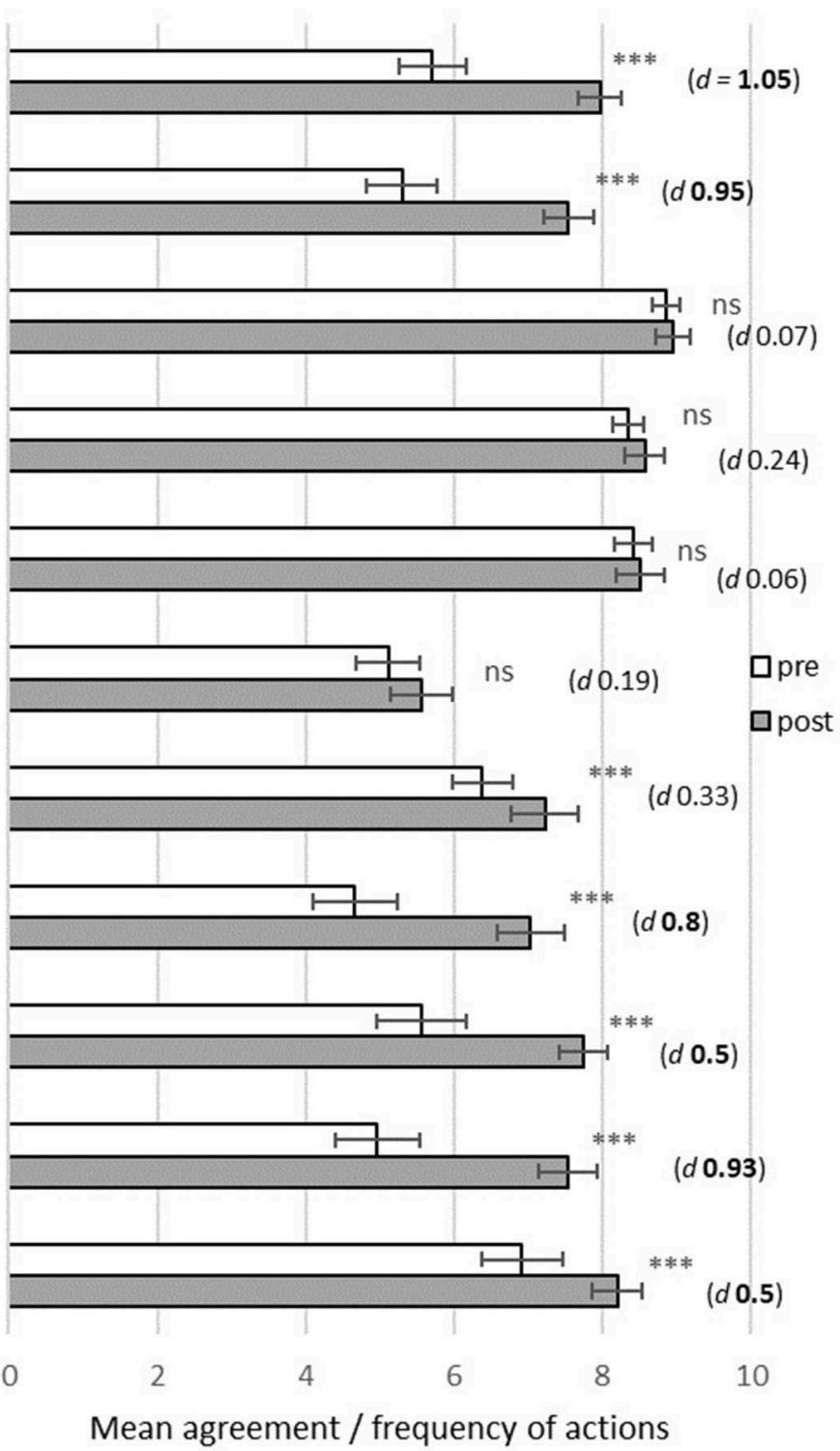

Mean agreement / frequency of actions

FIGURE 2 | Mean participant responses to pre and post surveys completed before and after viewing the "Rethinking plastic" film, significant differences $(p \leq 0.005)$ between pre and post surveys are indicated by ${ }^{\star \star \star}$, effect size (Cohen's $\left.d\right)$ of medium or above are in bold $(d=\#)$.

frequency of behaviors revealed acceptable internal reliability (current frequency responses 0.719 , intended frequency responses, 0.759).

\section{Pre-existing Environmental Connectedness}

Participants level of pre-existing concern for damage to the natural environment was high at the start of the study (mean) and remained high $t_{(32)}=0.47, p=0.64, d=0.07$ (Figure 2).

\section{Influence of Knowledge, Awareness, and Attitude Ocean Literacy Dimensions on Intended Behavior}

For post course responses, linear regression calculations provided a strong positive relationship between knowledge and attitude predictors of behavior change and intended behavior options specific to reducing use of microplastics. Participant's level of response to knowledge and attitude ocean literacy dimension questions were significant $(p \leq 0.005)$ in predicting the level of participants reported level of intended frequency of undertaking the behavior "look for products that do not contain microplastics" (Table 8). Small or moderate relationships were present, for knowledge and attitude responses in relation to predicting participants reported level of intended frequency of undertaking other behavior options to "reduce effects of microplastics in the sea" (Table 8). Although relationships were not significant with Bonferroni correction $(p \leq 0.005)$, moderately high $r^{2}$ values were returned in relation to participant's level of self-reported knowledge of effects on the environment as a predictor of intention to frequently support campaigns that aimed to reduce 
use of products with microplastics $\left(r^{2} 0.473, p=0.007\right)$. Small positive relationships was also identified for participants level of concern for the effects of microplastics on marine life and belief in benefits from taking action to reduce use of products with microplastics, as predictors of intended frequency to, "support shops that don't sell microplastics" and, "support for campaigns to reduce use of microplastics" (Table 8 ).

\section{Differences Between Age Groups and Location}

Greater mean support for intended frequency of undertaking behavior options in post surveys, was displayed by the older age group (16-18) in comparison to the younger age group (1115), apart from for the intended behavior, "separate plastics for recycling." No differences between groups were significant ( $p \leq$ 0.005) (Table 9).

Intended frequency of undertaking behavior options were higher for participants in Tulcea, Romania. However, no significant differences ( $p \leq 0.005$ ) were observed between locations (Tulcea, Romania and Plymouth, UK) (Table 10).

\section{DISCUSSION}

\section{Main Findings}

For both pilot studies the pre and post surveys indicate an effective shift along the stages in the theory of change, from knowledge to intended behavior. Where indicators of objectives for a stage in the theory of change had not been met in responses to pre surveys, objectives were met in post survey responses, following interaction with the tool. As knowledge, attitude (concern and belief in benefit from taking personal action) and intended behavior objectives were met for both tools, the results suggest that the tools were effective at promoting ocean literacy and behavior change goals for the participants in the case study examples.

Following the ocean literacy initiatives, participants intended behavior, showed strong support for undertaking behaviors that would address the relevant environment issues, relating to human-ocean relationships. Increase in support for behaviors relating to the topics was significant between pre and post surveys, with large positive effect sizes for each initiative. Intended frequency of undertaking behaviors, not actual objective behavior was collected. Thereby, the consideration of the predictors of behavior change, identified by Klöckner (2013), are likely to be as influential in assessing the effectiveness of the ocean literacy initiatives as relying on self-reported behavior intention alone. Increases in both pilot studies, in participant's knowledge of effects of human activities on the ocean, and the resulting effects on human well-being, as well as participant's level of concern for those effects and belief that action needs to be taken, also provide evidence of effectiveness of the initiatives.

The pilot studies demonstrate that the application of predictors of behavior change, as indicators within a theory of change framework, provides a means to monitor achievement of objectives in relation to ocean literacy, identified within the United Nations (2018) revised roadmap for the "decade of ocean science for sustainable development." United Nations (2018) considered that, "increased awareness and ocean literacy will be instrumental in triggering behavioural changes, such as adaptation of lifestyles, joining non-government organisations (NGOs), choosing ocean-affiliated professions" (United Nations, 2018). In particular, for the major target audience (school children) and professional stakeholders, the pilot studies demonstrate the potential to assess the effectiveness of ocean literacy programmes to trigger behavior change, such as lifestyle decisions or supporting campaigns or NGOs. The framework tested in the pilot studies, therefore, provides a means of assessing effectiveness of ocean literacy programmes on target audiences.

\section{Theory of Change-Intended Behavior and Predictors of Behavior Change}

Intentions ("I will do this"), and perceived behavioral control ("It is up to me whether I do this rather than other people or contextual factors") are reviewed by Klöckner (2013) to both be in the category of "best predictors of behavior change," based on review of environmental psychology literature. These predictors of behavior change occur in the Theory of Change as the behavior change objective, and one of two attitude objectives [participant's "belief there is a benefit if I (they) undertake the action (an action relating to the behavior change objectives")]. Intended behavior has been shown to correspond with self-reported behavior in studies that have followed up with participants, but to show much less correspondence with objectively recorded behavior, such as observed behavior (Eccles et al., 2006). The combination of increases in all objectives for each predictor of behavior change, not just intended behavior change, provides greater confidence in the effectiveness of the initiatives. These findings are important to consider for ocean literacy initiatives and have been shown in relation to research into pro-environmental behavior change.

Multiple influencing factors are recognized to lead to proenvironmental behaviors by industry actors. A study of bait shop owners engagement in outreach activities to promote behaviors to reduce spread of invasive species displayed level of engagement depended on a combination of predisposing factors (Howell et al., 2014). High level of intention to engage in activities resulted in high level of actual engagement. However, results of a path model, investigating predictors of actual behavior, revealed intention to undertake the behavior did not solely account for actual undertaking of the behavior (Howell et al., 2014). High level of concern for the consequences (attitude), pressure from social networks (communication/social norm), perceived behavioral control and self-efficacy also had a significant effect on actual engagement with activities (Howell et al., 2014). In the results from the "Sustainable Seafaring" course we present here, the combination of objectives being met in addition to intended behavior are of great importance. Knowledge, attitude (concern for consequences and belief in benefits of taking action) and communication dimension objectives are met as well as the intended behavior objective, providing greater confidence that the behavior change goals will be achieved.

Multiple factors, including a significant increase in knowledge, supportive attitude, and significant increase in intended behavior suggests interaction of school students with the ocean literacy film "Rethinking Plastic" met behavior change objectives. As 
TABLE 8 | Regression calculations to assess extent to which predictors of behavior change (awareness, knowledge, attitude, self-efficacy and social norm) predict participants self-reported intended frequency of undertaking behaviors or actions to reduce the effects of microplastics on marine life.

\begin{tabular}{|c|c|c|c|c|c|c|c|c|c|}
\hline \multirow{2}{*}{$\begin{array}{l}\text { Ocean literacy dimension, } \\
\text { correlated with intended } \\
\text { behavior }(0-10)\end{array}$} & \multicolumn{3}{|c|}{ Knowledge (environment) } & \multicolumn{3}{|c|}{ Attitude (concern effects) } & \multicolumn{3}{|c|}{ Attitude (belief benefits) } \\
\hline & $\boldsymbol{F}$ & $P$ & $r^{2}$ & $\boldsymbol{F}$ & $P$ & $r^{2}$ & $\boldsymbol{F}$ & $P$ & $r^{2}$ \\
\hline $\begin{array}{l}\text { "Look for products that don't } \\
\text { contain microplastics" }\end{array}$ & 16.984 & $<0.0005^{\star \star \star}$ & 0.369 & 20.52 & $<0.0005^{\star \star \star}$ & 0.414 & 24.3 & $<0.0005^{\star \star \star}$ & 0.456 \\
\hline $\begin{array}{l}\text { "Support shops that's don't sell } \\
\text { microplastics" }\end{array}$ & 6.96 & 0.013 & 0.193 & 6.47 & 0.017 & 0.182 & 7.59 & 0.01 & 0.208 \\
\hline "Support campaigns (0-10)" & 8.36 & 0.007 & 0.473 & 8.24 & 0.008 & 0.221 & 4.64 & 0.04 & 0.138 \\
\hline
\end{tabular}

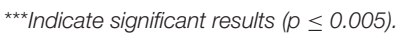

TABLE 9 | Mean intended frequency of each age group to undertake behavior options in the future, including Welch's $t$-test of difference between groups.

\begin{tabular}{|c|c|c|c|}
\hline Behavior or action & $\begin{array}{l}\text { Mean response (post) } \\
(11-15 \text { age category) }\end{array}$ & $\begin{array}{l}\text { Mean response (post) } \\
\text { (16-18 age category) }\end{array}$ & Welch's $t$-test \\
\hline Look for products that use recycled packaging & $7.16 \mathrm{SE} \pm 0.58$ & $7.9 \mathrm{SE} \pm 0.5$ & $t_{(27)} 0.96, p=0.34$ \\
\hline Look for products that do not contain microplastics & $6.83 \mathrm{SE} \pm 0.63$ & $7.75 \mathrm{SE} \pm 0.59$ & $t_{(25)} 1.04, p=0.31$ \\
\hline $\begin{array}{l}\text { Support shops and brands that don't sell products } \\
\text { containing microplastics }\end{array}$ & 7.3 SE \pm 0.46 & $8.5 \mathrm{SE} \pm 0.4$ & $t_{(27)} 1.95, p=0.06$ \\
\hline $\begin{array}{l}\text { Support campaigns to ban the sale or use of } \\
\text { microplastics in products }\end{array}$ & $7.07 \mathrm{SE} \pm 0.55$ & $8.5 \mathrm{SE} \pm 0.5$ & $t_{(27)} 1.92, p=0.07$ \\
\hline Separate plastics for recycling & 8.26 SE \pm 0.45 & 7.7 SE \pm 0.58 & $t_{(20)} 0.77, p=0.45$ \\
\hline
\end{tabular}

discussed, intention to complete an action, when combined with attitudes supporting the behavior, is more likely to result in an action being undertaken (Klöckner, 2013; Howell et al., 2014). In the case of the school students, where mean levels of concern for consequences and belief in a benefit from taking personal action were already high, the information provided by the film its self on the details of the effects of microplastic pollution, and the actions that could be taken appears important. After viewing the film there was a significant increase in selfreported knowledge (of effects of microplastics on marine life and (potential) consequences for human health). There were also significant increases in intention to undertake behavior options that specifically reduce use of products containing microplastics. Regression analysis found level of knowledge was a significant predictor, as well as level of attitudes of concern and belief in benefits from personal action, in predicting intended frequency to "look for products that do not contain microplastics." Actions to actively reduce microplastic use appeared to be relatively new behavior options to the students. Average frequency of undertaking behavior options that were likely to already be available to them before viewing the film, such as separating plastics for recycling, was already high. In comments replying to "where did you hear about these options" influence from school, wildlife clubs, T.V. and parent's behavior were mentioned in before studies and "here at the (national marine) aquarium" was increasingly mentioned after viewing the film. The higher reported and intended frequency in pre and post surveys by younger school students (11-15) to undertake the action "separate plastics for recycling may represent that this is a more commonly adopted behavior in households." Intended frequency of undertaking newer behaviors, directed at reducing or eliminating use of products containing microplastics was greater for the older school students (16-18). Pre-existing concern for the natural environment and concern for the impacts of microplastics on the marine environment were greater for the older school students and may suggest this difference, as well as understanding of terminology such as microplastics.

Ocean literacy initiatives around marine litter have previously been shown to influence pro-environmental behavior in school students. Younger school students reported performing more waste reduction behaviors following interaction with a marine litter initiative (Hartley et al., 2015). Results suggested the initiative had also boosted understanding of the causes and impacts of marine litter. The findings we present, support this, and although self-reported behavior post interaction was not collected in the surveys we report, all objectives for predictors of behavior change were met, apart from for "communication."

Although predictors of behavior change identified by Klöckner (2013) were from reviewed studies involving adults, they reflect central concepts in children's environmental education. Effectiveness of environmental education has been reviewed by Rickinson (2001) to be supported by six nodes, most recognized were students' (i) environmental knowledge (ii) environmental attitudes and behaviors, and (iii) environmental learning outcomes, while three were regarded as emerging: students' (i) perceptions of nature, (ii) experiences of learning, and (iii) influences on adults. As an education tool, the survey results, suggest the "Rethinking Plastic" film met objectives relating to the three most recognized nodes. 


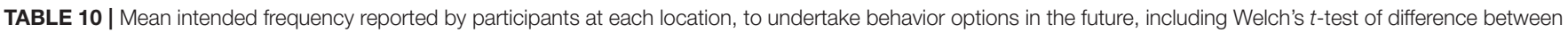
groups.

\begin{tabular}{|c|c|c|c|}
\hline Behavior or action & $\begin{array}{c}\text { Mean response } \\
\text { (respondents in Plymouth, UK) }\end{array}$ & $\begin{array}{l}\text { Mean response } \\
\text { (respondents in Tulcea, Romania) }\end{array}$ & Welch's $t$-test \\
\hline Look for products that use recycled packaging & $6.89 \mathrm{SE} \pm 0.72$ & $7.93 \mathrm{SE} \pm 0.42$ & $t_{(24)} 1.25, p=0.22$ \\
\hline Look for products that do not contain microplastics & 7.03 SE \pm 0.75 & $7.23 \mathrm{SE} \pm 0.58$ & $t_{(28)} 0.21, p=0.83$ \\
\hline $\begin{array}{l}\text { Support shops and brands that don't sell products } \\
\text { containing microplastics }\end{array}$ & $7.28 \mathrm{SE} \pm 0.58$ & $8.13 \mathrm{SE} \pm 0.36$ & $t_{(25)} 1.25, p=0.22$ \\
\hline $\begin{array}{l}\text { Support campaigns to ban the sale or use of } \\
\text { microplastics in products }\end{array}$ & $7.0 \mathrm{SE} \pm 0.65$ & $8.1 \mathrm{SE} \pm 0.51$ & $t_{(28)} 1.33, p=0.19$ \\
\hline Separate plastics for recycling & 8.0 SE \pm 0.56 & 8.17 SE \pm 0.45 & $t_{(28)} 0.23, p=0.82$ \\
\hline
\end{tabular}

Self-reported frequency of communication did not meet the objectives for either study. However, there was small increase in both studies which is likely to have a small multiplier effect, in cases where participants are likely to share information they have learnt and promote intended behaviors. For the school student group, this small increase may be very effective in reaching multipliers. Influences on adults (or "pester power") from young people is highlighted by Hartley et al. (2015) as being a recognized means of influencing family members, peers and the wider community, long identified by marketing and consumer research (Wilson and Wood, 2004; Flurry and Burns, 2005). Although the association for marine litter related behaviors has not been tested, such relationships have been show in wider conservation topics. For instance, greater awareness and knowledge of parents has been related to children's environmental education in relation to other environmental education topics, such as importance of wetlands (Damerell et al., 2013).

The small increase in reported frequency of communication on the topic may be related to post interaction surveys only being undertaken within $24 \mathrm{~h}$ of school students interacting with the "Rethinking Plastic" film and engineering college students interacting with the "Sustainable Seafaring" course. This provided limited time for participants to actually discuss the topic with friends, family and colleagues. Completing, or following up the after survey, even up to a week or month after the event may have changed this result, and also allowed for reporting on change in reported as well as intended frequency of undertaking each behavior.

\section{Improving Experimental Approaches}

The assessment of effectiveness of behavior change objectives would benefit from follow-up surveys to record self-reported behavior in the months after interaction with the initiative. This would also allow researchers to assess if the behavior was also becoming habitual, a key predictor of long-term behavior change (Klöckner, 2013). As surveys were completed in the presence of course tutors or educators, there may be a risk of social desirability bias. The behavior options have been demonstrated by the film or course and support of these may be felt to be desired by the course leaders or educators, as well as being the socially expected response (Brenner and DeLamater, 2016).

To fully assess long term accomplishment of behavior change objectives would require additional objective indicator data, such as observational data. As recognized in the review work by Klöckner (2013), understanding change in an individual's habits (behaviors that have become automatized through repetition), is also amongst the best direct predictors of behavior change (Table 1). Examples of methods that could be applied, include observing individual's behavior in supermarkets in relation to purchasing choice, as applied for plastic bag use by Jakovcevic et al. (2014), or frequency of undertaking a behavior such as littering in parks (Schultz et al., 2013). For participants of an ocean literacy initiative with an associated app or social media site, frequency of visits to the social media site or of accessing information resources on an app within smart phones can be undertaken (Ernsting et al., 2017; Dempsey et al., 2018).

It would also be beneficial to compare the treatment group to a control group who do not interact with the ocean literacy intervention. As Pahl and Wyles (2017) discuss, this would allow identification of other external factors which could account for the any change identified over time. It would also add to the assessment if participant's from broader backgrounds were included, as participants of existing pilot studies showed moderate to high pre-existing concern for damage to the marine environment, although this could not necessarily be ascertained before the pilot study. A "rigorous ocean literacy programme of activities" intended to approach all actors, from school age children to governments, as identified by United Nations (2018), would need to be implemented across participants with different levels of pre-existing pro-environmental attitudes, and similarly the assessment be conducted across all groups.

Follow up surveys would also benefit from addressing the barriers and enabling factors for adoption of new behaviors. Understanding the barriers to adoption of behavior would potentially aid addressing the limited increase observed in selfefficacy between pre and post surveys by young professionals (seafarers) sample. Self-efficacy has been shown to be an important area to considering addressing ocean literacy of professionals. Actual adoption of climate change initiatives by farmers was shown to depend on perceived capacity and selfefficacy, while attitudes such as concern and belief in benefits from action were only associated with intended not actual adoption (Niles et al., 2016). Participants of the seafaring course raised the point in workshop sessions, that they will be junior officers when they start work on board ships and will have to follow orders or protocol set out by superior officers or the 
ship owners. Addressing ocean literacy around industry specific topics, would appear to benefit from targeting actors involved across the industry, including, experienced officers and ship owners as well as young career professionals.

\section{CONCLUSIONS}

For both studies, pre and post surveys provided a means of assessing indicators of effective shifts along the stages in a Theory of Change, from knowledge to intended behavior, for participants encountering an ocean literacy initiative. As knowledge, attitude, such as concern and belief in benefit from taking personal action, and intended behavior objectives were met tools, and not just intended behavior or even just awareness, the approach provides greater confidence that the ocean literacy initiative has effected behavior change objectives. The approach, thereby, benefits from taking into account multiple predictors of behavior change.

The results display the effectiveness of applying the pre and post survey approach, within a theory of change model where each stages identifies each predictor of behavior change. The results of surveys demonstrated the effectiveness of tools on small sample groups of different actors. Although, with such small sample sizes, conclusions for effectiveness of the tools across a population level cannot be made, the approach is beneficial in building evidence of effectiveness. The approach identified the pre-existing pro-environmental attitudes held by the school students attending the National Marine Aquarium event. The survey approach was able to demonstrate the benefit of providing specific knowledge on the cause and effect of microplastics entering the sea and the consequences for marine life and human health. Displaying specific actions the viewers could take to reduce the problem appears important at providing knowledge on actions and their benefits that could be taken, encouraging the students pre-existing attitudes to support actions.

The approach, demonstrated the effectiveness of a 2 day course, for early career seafarers (engineer and deck officers), dedicated to wider ocean literacy knowledge about the ocean environment and the impacts of invasive non-native species. Comparison of pre and post survey results was able to demonstrate the effectiveness of the course in raising levels of knowledge, and also attitudes of greater concern and belief in benefit from action, and to undertake intended behavior. The approach identified some limitations in capability of early career professionals to change industry behavior, and that self-efficacy was limited by decisions of superior officers and ship owners.

The study supports earlier research, that identifies that ocean literacy initiatives (and wider environmental education), when tailored to relevant issues and actors, increases knowledge and attitudes of greater concern and belief that personal action will bring benefits. Future application of pre and post survey techniques to assess change in predictors of behavior change in relation to ocean literacy interventions would benefit from also undertaking longer term assessment of indicators, including participant's self-reported behavior, and also collecting objective observational data. The study also identified that approaching all actors that can influence a human-ocean relationship will bring wider benefits. Ultimately the young career seafarers identified that their action may be beneficial. However, these respondents also identified that change in attitude and behavior of shipping companies and governments to support actions is required for problems to be fully addressed.

\section{ETHICS STATEMENT}

This study was carried out in accordance with the recommendations of Research Ethics Policy of University of Plymouth Science and Engineering Faculty Research Ethics and Integrity Committee with written informed consent from all subjects. All subjects gave written informed consent in accordance with the Declaration of Helsinki. The protocol was approved by the University of Plymouth Science and Engineering Faculty Research Ethics and Integrity Committee.

\section{AUTHOR CONTRIBUTIONS}

MA, SP, and GG contributed to the design and implementation of the study. SF contributed to report written content. MA analyzed the data and prepared the report.

\section{FUNDING}

This project has received funding from the European Union's Horizon 2020 Framework Programme for Research and Innovation (H2020-BG-2014-1) under grant agreement No. 652643.

\section{ACKNOWLEDGMENTS}

We would like to thank Owen Molloy and Conor McCrossan of National University Ireland -Galway, for collaboration on identifying the ocean literacy dimensions applied in the framework. Thank you too to Louise Ras at Oceanopolis Aquarium Brest, France for feedback and help designing survey questions for young audiences, including pre-testing and SF of UN Environment World Conservation Monitoring Center and University of Plymouth for feedback on the framework. We would like to thank Joeseph Farrow of National Marine Aquarium, Plymouth for integrating the pre and post surveys with National Marine Aquarium, Plymouth events, as well as Edward Bratfanof (Danube Delta National Institute for Research and Development, Tulcea, Romania for organizing school events and pre and post surveys in high schools in Tulcea. Thank you too to Nick Rance and the team at TVE for their work developing the Rethinking Plastic film and assistance developing theory of change objectives for the film. We would also like to thank Erik Bogaard and Jerry Lust at ProSEA for integrating the survey within the Sustainable Seafaring course and assistance developing the Theory of change objectives. Thank you too to all within the EU Horizon 2020 project ResponSEAble, without which this work would not have been possible. 


\section{REFERENCES}

Andriamalala, G., Peabody, S., Gardner, C. J., and Westerman, K. (2013). Using social marketing to foster sustainable behaviour in traditional fishing communities of southwest Madagascar. Conserv. Evidence 10, 37-41.

Beanland, C., Schneider, Z., LoBiondo-Wood, G., and Haber, J. (1999). Nursing Research: Methods, Critical Appraisal and Utilisation. Sydney, NSW: Mosby.

Bishop, T., Seys, J., Sousa-Pinto, I., Tuddenham, P., and Van Medegael, L. (2015). "Review of routes of engagement between citizens and ocean literacy," in $E U$ Sea Change Project. Available online at http://www.seachangeproject.eu

Brenner, P. S., and DeLamater, J. (2016). Lies, damned lies, and survey selfreports? Identity as a cause of measurement bias. Soc. Psychol. Q. 79, 333-354. doi: $10.1177 / 0190272516628298$

Buckley, P. J., Pinnegar, J. K., Painting, S. J., Terry, G., Chilvers, J., Lorenzoni, I., et al. (2017). Ten thousand voices on marine climate change in europe: different perceptions among demographic groups and nationalities. Front. Marine Sci. 4:206. doi: $10.3389 /$ fmars.2017.00206

Chaigneau, T., and Daw, T. M. (2015). Individual and village-level effects on community support for Marine Protected Areas (MPAs) in the Philippines. Marine Pol. 51, 499-506. doi: 10.1016/j.marpol.2014.08.007

Chen, C. L., and Tsai, C. H. (2016). Marine environmental awareness among university students in Taiwan: a potential signal for sustainability of the oceans. Environ. Edu. Res. 22, 958-977. doi: 10.1080/13504622.2015.1054266

Connell, J. P., and Kubisch, A. C. (1998). "Applying a theory of change approach," in New Approaches to Evaluating Community Initiatives. Theory, Measurement, and Analysis, eds K. Fulbright Anderson, A. C. Kubisch, and J. P. Connell. (Washington, DC: Aspen Institute), 1-13.

Cronbach, L. J. (1990). Essentials of Psychological Testing. 5th Edn. New York, NY: Harper \& Row.

Damerell, P., Howe, C., and Milner-Gulland, E. J. (2013). Child-orientated environmental education influences adult knowledge and household behaviour. Environ. Res. Lett. 8:015016. doi: 10.1088/1748-9326/8/1/015016

Dempsey, R. C., McAlaney, J., and Bewick, B. M. (2018). A critical appraisal of the social norms approach as an interventional strategy for health-related behavior and attitude change. Front. Psychol. 9:2180. doi: 10.3389/fpsyg.2018.02180

Donert, K., Fauville, G., Gotensparre, S., Mäkitalo, Å., Van Medegael, L., and Zwartjes, L. (2015). "Review of marine formal education," in EU Sea Change Project. Available online at http://www.seachangeproject.eu

Eccles, M. P., Hrisos, S., Francis, J., Kaner, E. F., Dickinson, H. O., Beyer, F., et al. (2006) Do self- reported intentions predict clinicians' behaviour: a systematic review. Implementation Sci. 1, 28-28. doi: 10.1186/1748-5908-1-28

ELL (2007). Environmental Literacy Ladder. Available online at: http://www. fundee.org/facts/envlit/whatisenvlit.htm

Elliott, M., Burdon, D., Atkins, J. P., Borja, A., Cormier, R., de Jonge, V. N., et al. (2017). "And DPSIR begat DAPSI(W)R(M) !"-A unifying framework for marine environmental management. Marine Pollut. Bull. 118, 27-40. doi: 10.1016/j.marpolbul.2017.03.049

Ernsting, C., Dombrowski, S. U., Oedekoven, M., O, Sullivan, J. L., Kanzler, M., Kuhlmey, A., et al. (2017). Using smartphones and health apps to change and manage health behaviors: a population-based survey. J. Med. Internet Res. 19:e101. doi: 10.2196/jmir.6838

Fauville, G., Strang, C., Cannady, M. A., and Chen, Y.-F. (2018). Development of the International Ocean Literacy Survey: measuring knowledge across the world. Environ. Edu. Res. 3, 1-26. doi: 10.1080/13504622.2018.1440381

Fletcher, S., and Potts, J. (2007). Ocean citizenship: an emergent geographical concept. Coast. Manag. 35, 511-524. doi: 10.1080/08920750701525818

Flurry, L. A., and Burns, A. C. (2005). Children's influence in purchase decisions: a social power theory approach. J. Business Res. 58, 593-601. doi: 10.1016/j.jbusres.2003.08.007

Gelcich, S., Buckley, P., Pinnegar, J. K., Chilvers, J., Lorenzoni, I., Terry, G., et al. (2014). Public awareness, concerns, and priorities about anthropogenic impacts on marine environments. Proc. Natl. Acad. Sci. U.S.A. 111, 15042-15047. doi: $10.1073 /$ pnas. 1417344111

Green, L. W., and Kreuter, M. W. (1999). Health Promotion and Planning: An Educational and Environmental Approach. Mountain View, CA: Mayfield Publishing Co.

Hartley, B. L., Pahl, S., Holland, M., Alampei, I., Veiga, J. M., Thompson, R. C. (2018a). Turning the tide on trash: empowering European educators and school students to tackle marine litter. Marine Policy 96, 227-234. doi: 10.1016/j.marpol.2018.02.002

Hartley, B. L., Pahl, S., Veiga, J., Vlachogianni, T., Vasconcelos, L., Maes, T., et al. (2018b). Exploring public views on marine litter in Europe: perceived causes, consequences and pathways to change. Marine Pollut. Bull. 133, 945-955. doi: 10.1016/j.marpolbul.2018.05.061

Hartley, B. L., Thompson, R. C., and Pahl, S. (2015). Marine litter education boosts children's understanding and self-reported actions. Marine Pollut. Bull. 90, 209-217. doi: 10.1016/j.marpolbul.2014.10.049

Hawthorne, M., and Alabaster, T. (1999). Citizen 2000: development of a model of environmental citizenship. Global Environm. ChangeHuman Policy Dimensions 9, 25-43. doi: 10.1016/S0959-3780(98) 00022-3

Howell, A. P., Shaw, B. R., and Alvarez, G. (2014). Bait shop owners as opinion leaders: a test of the theory of planned behavior to predict pro-environmental outreach behaviors and intentions. Environ. Behav. 47, 1107-1126. doi: $10.1177 / 0013916514539684$

Jakovcevic, A., Steg, L., Mazzeo, N., Caballero, R., Franco, P., Putrino, N., et al. (2014). Charges for plastic bags: motivational and behavioral effects. J. Environ. Psychol. 40, 372-380. doi: 10.1016/j.jenvp.2014.09.004

Jenks, B., Vaughan, P. W., and Butler, P. J. (2010). The evolution of Rare Pride: using evaluation to drive adaptive management in a biodiversity conservation organization. Evaluat. Program Planning 33, 186-190. doi: 10.1016/j.evalprogplan.2009.07.010

Klöckner, C. A. (2013). A comprehensive model of the psychology of environmental behaviour-a meta-analysis. Global Environ. Change-Human Policy Dimensions 23, 1028-1038. doi: 10.1016/.j.gloenvcha.2013.05.014

Muderrisoglu, H., and Altanlar, A. (2011). Attitudes and behaviors of undergraduate students toward environmental issues. Int. J. Environ. Sci. Technol. 8, 159-168. doi: 10.1007/BF03326205

Niles, M. T., Brown, M., and Dynes, R. (2016). Farmer's intended and actual adoption of climate change mitigation and adaptation strategies. Clim. Change 135, 277-295. doi: 10.1007/s10584-015-1558-0

Pahl, S., and Wyles, K. J. (2017). The human dimension: how social and behavioural research methods can help address microplastics in the environment. Anal. Methods 9, 1404-1411. doi: 10.1039/C6AY02647H

Pilot, D., and Hungler, B. (1999). Nursing Research: Principals and Methods. Philadelphia, PA: Lippincott Williams \& Wilkins.

Potts, T., Pita, C., O'Higgins, T., and Mee, L. (2016). Who cares? European attitudes towards marine and coastal environments. Marine Policy 72, 59-66. doi: 10.1016/j.marpol.2016.06.012

Prochaska, J. O., Diclemente, C. C., and Norcross, J. C. (1992). In search of how people change-applications to addictive behaviours. Am. Psychol. 47, 1102-1114. doi: 10.1037/0003-066X.47.9.1102

Reddy, S. M. W., Montambault, J., Masuda, Y. J., Keenan, E., Butler, W., Fisher, J. R. B., et al. (2016). Advancing conservation by understanding and influencing human behavior. Conserv. Lett. 10, 248-256. doi: 10.1111/conl.12252

ResponSEAble (2015). ResponSEAble Project. Available online at: https://www. responseable.eu/

Rickinson, M. (2001). Learners and Learning in Environmental Education: a critical review of the evidence AU-Rickinson, Mark. Environ. Education Res. 7, 207-320. doi: 10.1080/13504620120065230

Saypanya, S., Hansel, T., Johnson, A., Bianchessi A., and Sadowsky B. (2013). Effectiveness of a social marketing strategy, coupled with law enforcement, to conserve tigers and their prey in Nam Et Phou Louey National Protected Area, Lao People’s Democratic Republic. Conserv. Evid. 10, 57-66.

Schoedinger, S., Cava, F., Strang, C., Tuddenham, P. (2005). Ocean literacy through Science Standards. Oceans 1-3, 736-740. doi: 10.1109/OCEANS.2005.1639840

Schubel, J. R., and Schubel, K. A. (2008). From ocean issues to solutions: the role of public ocean literacy. Oceans 1-4, 524-545. doi: 10.1109/OCEANS.2008.5151878

Schultz, P. W. (1999). Changing behavior with normative feedback interventions: a field experiment on curbside recycling. Basic Appl. Soc. Psychol. 21, 25-36. doi: 10.1207/s15324834basp2101_3

Schultz, P. W., Bator, R. J., Large, L. B., Bruni, C. M., Tabanico, J. J. (2013). Littering in context: personal and environmental predictors of littering behavior. Environ. Behav. 45, 35-59. doi: 10.1177/0013916511 412179 
Steg, L., Van den Berg, A. E., and De Groot, J. I. M. (2013). Environmental Psychology: An Introduction. Chichester: John Wiley \& Sons Ltd.

United Nations (2018). Revised Roadmap for the UN Decade of Ocean Science for Sustainable Development.

Vaughan, P. W., and Rogers, E. M. (2000). A staged model of communication effects: evidence from an entertainment-education radio soap opera in Tanzania. J. Health Commun. 5, 203-227. doi: 10.1080/108107300501 31398

Wilson, G., and Wood, K. (2004). The influence of children on parental purchases during supermarket shopping. Int. J. Consumer Stud. 28, 329-336. doi: $10.1111 / \mathrm{j} .1470-6431.2004 .00393 . x$
Conflict of Interest Statement: The authors declare that the research was conducted in the absence of any commercial or financial relationships that could be construed as a potential conflict of interest.

Copyright (C) 2019 Ashley, Pahl, Glegg and Fletcher. This is an open-access article distributed under the terms of the Creative Commons Attribution License (CC BY). The use, distribution or reproduction in other forums is permitted, provided the original author(s) and the copyright owner(s) are credited and that the original publication in this journal is cited, in accordance with accepted academic practice. No use, distribution or reproduction is permitted which does not comply with these terms. 